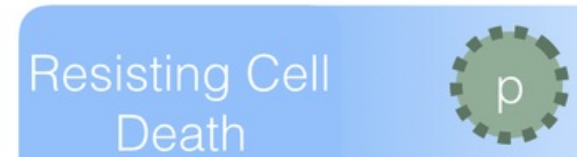

see „Inducing Angiogenesis“

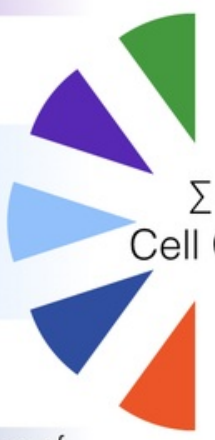

average of gene expression

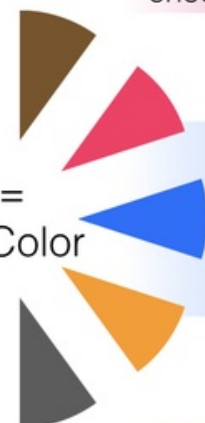

expression of „Enabling Replicative Immortality“

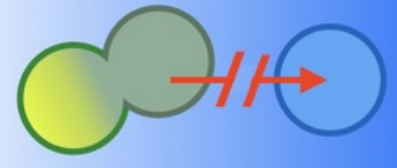

Enabling

Replicative

Immortality

decreases the value thats subtracted from a cell's current hayflick limit after proliferation

expression of „Tumor Promoting Inflammation increases the probability

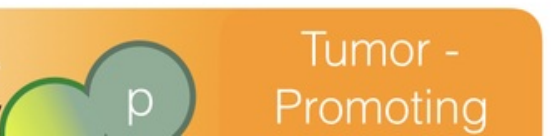

\title{
Understanding and Controlling Cancer: The Hallmark Concept Revisited - Chance, Evolution and Entropy
}

Authors: Jenny Groten, Christoph Borner, Roland Mertelsmann

Submitted:

6. November 2016

Published:

6. November 2016

Volume:

Issue:

3

Affiliation:

7

Keywords:

Albert-Ludwigs Universität, Freiburg

Cancer, carcinogenesis, evolution, entropy, cancer hallmarks, chance

DOI: $\quad$ 10.17160/josha.3.7.252

Journal of Science,

Humanities and Arts

JOSHA is a service that helps scholars, researchers, and students discover, use, and build upon a wide range of content 
Institut für Molekulare Medizin und Zellforschung (1)

Medizinische Klinik 1, Universitätsklinikum Freiburg (2)

Albert-Ludwigs-Universität Freiburg

\title{
Understanding and Controlling Cancer
}

The Hallmark Concept Revisited - Chance, Evolution and Entropy

\author{
Jenny Groten (1) \\ Christoph Borner (1)
}

Roland Mertelsmann (2) 
If you can't explain it simply, you don't understand it well enough.

- Albert Einstein (Anon 2016) 


\section{Abstract}

The overall aim of this investigation was to identify the fundamental phenotypic traits of a cancer cell to develop an "in silico" simulation model and, vice versa redefine the identified characteristics via the established simulation model. Thus, the focus lay on visualization and interactivity of the simulation. To achieve this aim, we addressed the following objectives.

In the present paper, the essential "Hallmarks of Cancer" have been identified, based on a literature review. The term "Hallmarks of Cancer" has thereby been adopted from Hanahan and Weinberg (Hanahan \& Weinberg 2000; Hanahan \& Weinberg 2011) and defines the most fundamental phenotypic characteristics of cancer cells, which are assumed to distinguish the latter from normal cells.

Aiming to achieve our concept of phenotypic cancer hallmarks, we also critically considered literature about the history of cancer research, the hallmarks selected by Hanahan and Weinberg, the genetic hallmarks, focusing on gene expression, the principles of evolution, entropy and chance in cancer, the principles of cancer treatment and recent research strategies. As a result, the identified hallmark characteristics were evaluated and, finally, synthesized.

\section{Table of Contents}

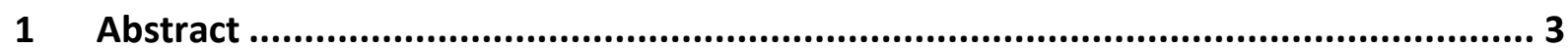

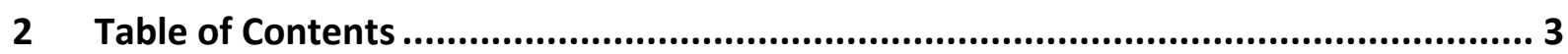

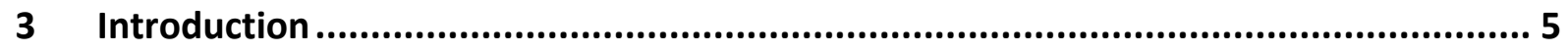

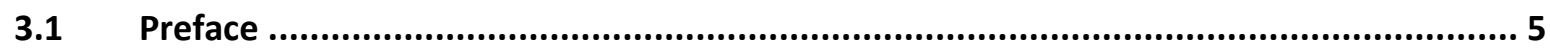

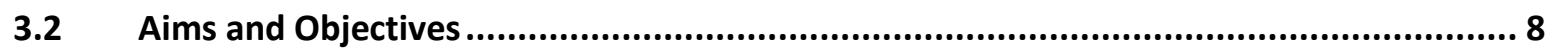

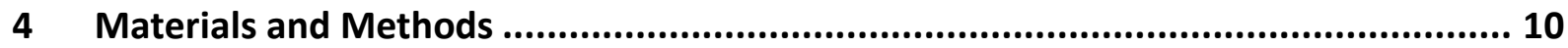

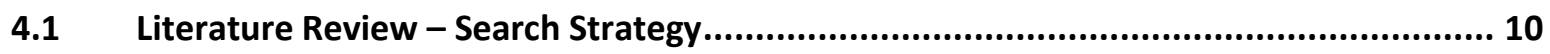

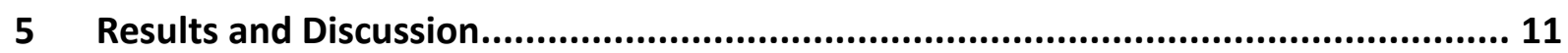

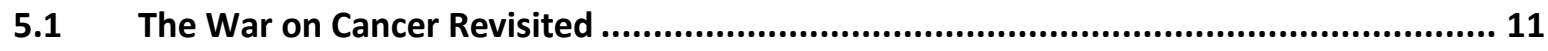

5.1.1 The Concept of Carcinogenesis through the Ages...................................................... 11

5.1.2 The Hallmarks of Cancer (Hanahan and Weinberg) ..................................................... 19 


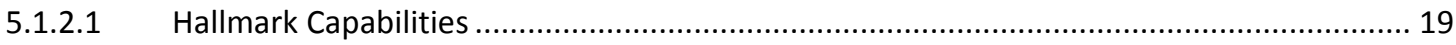

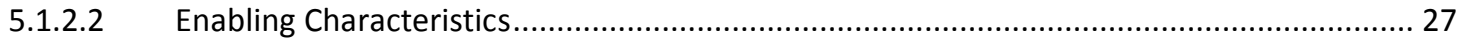

5.1.3 The Genetic Hallmarks of Cancer - Gene Expression Hallmarks................................. 29

5.1.4 Principles of Evolution and Entropy - Cancer as an evolutionary disease .................... 33

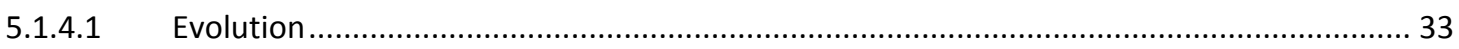

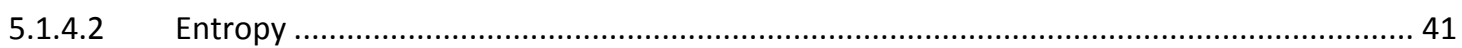

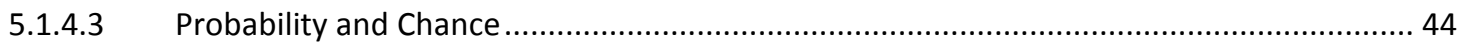

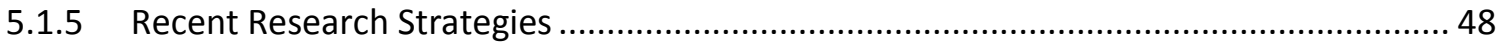

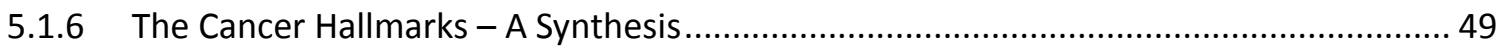

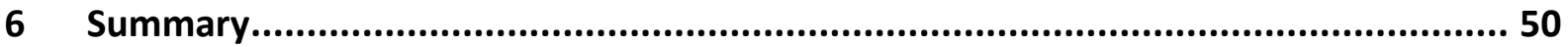

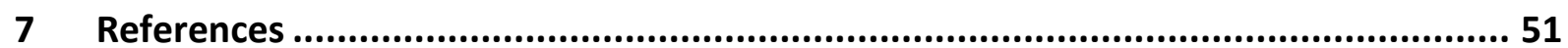

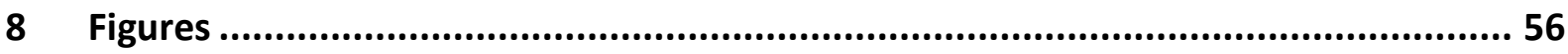

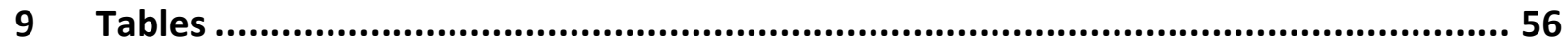

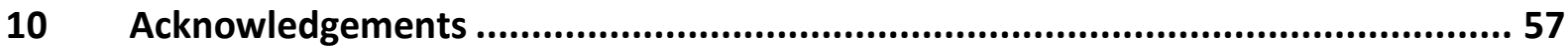




\section{Introduction}

This introduction is pertinent to the present and the following publication (Groten et al., 2016, in press)

\subsection{Preface}

"Cancer is a leading cause of death, and cancer incidence is expected to increase worldwide in the coming decades. But today, cancer research is on the cusp of major breakthroughs. It is of critical [...] importance that we accelerate progress towards prevention, treatment, and a cure -- to double the rate of progress in the fight against cancer -- and put ourselves on a path to achieve in just 5 years research and treatment gains that otherwise might take a decade or more." (Barack Obama, January 28, 2016)

With this statement, the President of the United States recently laid the foundations to reenter the fray against cancer (Obama 2016). Calling for a new initiative, headed by Vice-President Biden, he established the "White House Cancer Moonshot Task Force", consisting of members of various departments, to unite researchers, oncologists, patient representatives, economists, politicians and philanthropists in the envisaged revolution of the cancer research landscape (Lowy \& Collins 2016). In fact, cancer is still the second-leading cause of death after cardiovascular diseases in Germany (Bundesamt 2014) as well as worldwide (WHO 2016b). Cancer mortality rates apparently have diminished during the last 25 years (Lowy \& Collins 2016; IARC 2016b). However, according to the World Health Organization (WHO) the worldwide incidence of cancer is estimated to increase by about $70 \%$ in the next two decades, which means an absolute number of annual cancer cases of up to 22 million instead of 14 million in 2012 (WHO 2016a). In the face of these alarming data, one might assume that an international commitment to cure cancer once and for all is more than overdue. However, in fact, in the long struggle against cancer, it is not the first governmental attempt to raise the cancer issue on a national, and thereby, public and more intense level. On the contrary, it was President Franklin D. Roosevelt who established the National Cancer Institute $(\mathrm{NCl})$ with the help of the National Cancer Act of 1937 (National Cancer Institute 2016a). Later, on December 23, 1971, his successor President Richard Nixon signed into law the National Cancer Act of 1971 to make the "Conquest of Cancer [...] a national crusade". It should broaden the role of the National Cancer Institute 
$(\mathrm{NCl})$, at that time a part of the National Institutes of Health $(\mathrm{NIH})$, and extended its mandate to the future application of the research results to decrease the incidence, morbidity, and mortality due to cancer (National Cancer Institute 2016b). In Europe, several national and international associations with similar aims were founded. In 1933, the Union Internationale Contre le Cancer (UICC) was founded in Geneva (UICC 2014). Later, the International Agency for Research on Cancer (IARC) was established as the specialized cancer agency of the World Health Organization (WHO) (IARC 2016a). In Germany the Deutsches Krebsforschungszentrum (DKFZ) was formed in 1964 (Deutsches Krebsforschungszentrum 2016). The research objectives of the current campaigns, ranging from cancer vaccines to data sharing and the promotion of innovative and exceptional approaches, obviously reflect the urge to rethink the oncologic research landscape (Lowy \& Collins 2016). In the time of big data and information sharing the focus increasingly lies in data collection, analysis, evaluation and implementation. One compelling example is the massive decoding of the human cancer genome through next-generation DNA sequencing (Hayes \& Kim 2015). Paradoxically, at first sight, a major shift in patient care takes place at the same time, edging away from Evidence-Based Medicine (EBM) to a Personalized Medicine (PM) (Sugarman 2012). In PM, patients are individually diagnosed and treated with innovative treatments, far off the beaten track, are given a place. This movement can undoubtedly be rated as a major turning point in the history of cancer research, which has been focused on detecting regularities and defining classifications for a long time. Here, the role of Bioinformatics becomes inevitable to enable big data and PM to go hand by hand allowing novel and innovative perspectives, where traditional EBM has recognized its limitations. Knowledge and data regarding the carcinogenesis process and cancer treatment have increased dramatically and have finally reached an unmanageable complexity. Common lab experiments and clinical trial tools can no longer provide adequate opportunities to investigate carcinogenesis and cancer treatment as a whole or even 
its sheer endless number of subunits and possible interactions. A result is the reductionist approach leading to delusive selective insights into complex biologic processes, similar to the parable of the blind monks examining an elephant, who all fail to recognize the creature as a whole, since they only examined a small part each (Fig. 1). This approach, by far, does not satisfy cellular heterogeneity and "noise", two fundamental characteristics of cellular and system behavior (Walker \& Southgate 2009). Bioinformatics provides a solution, implementing mathematical models and information theory, which bring along massive computational power exceeding the limited capacity of the human mind, to address the complexity of data, correlations, and calculations. These so called in silico experiments and analyses are time-saving and, nevertheless, encompassing and lead to in-depth results. Thereby, analytical models can be distinguished from simulation models. Analytical models have experienced broad implementation during the last decade, for example, regression analyses have been used for statistical purposes, such as the prediction of affinity profiles of nucleic acid-binding protein from the protein sequence (Pelossof et al. 2015). In contrast, simulation models have hardly received attention, despite a broad and fruitful application in other disciplines, such as engineering, economics or some aspects of biology, where it has become the state-of-the-art solution for understanding and optimizing processes and complex systems (Suthaharan 2016; Sütterlin 2015). In both analytical and simulating model types, machine learning can be applied by means of self-teaching systems which are equipped with basic

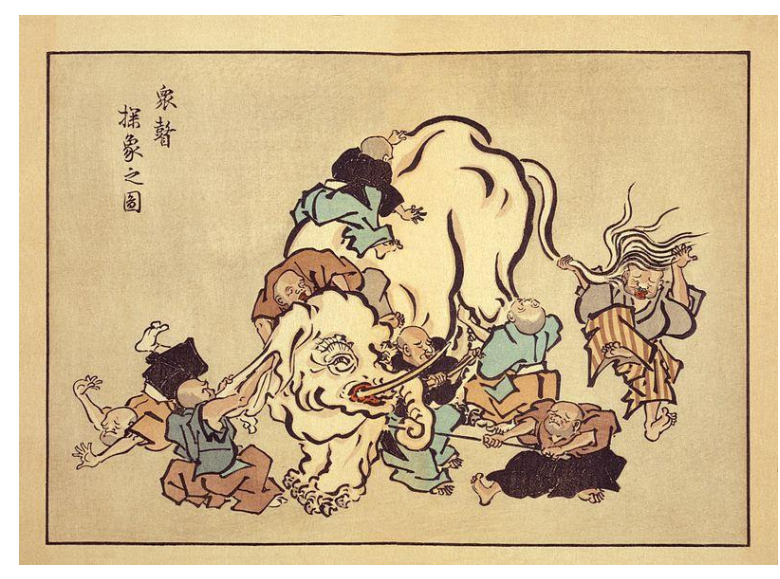

Figure 1 Blind monks examining an elephant, Hanabusa Itcho,

https://en.wikipedia.org/wiki/Blind_men_and_an_eleph ant, 2016 parameters, fundamental conditions and feedback mechanisms to evaluate target parameters. It shows the significant advantage of optimizing a process without an entire knowledge of the actual mechanisms, parameters, and measurements and, therefore, increases the probability of unexpected outcomes (Riedmiller et al. 2009). In comparison to analytical models, simulation models provide various benefits. Probably, the most essential aspect is the additional dimension of a simulation, time. This supplement allows the observation and calculation of a development over time and 
further enables the evaluation of data at any arbitrary point in time. Moreover, a simulation represents a tool to visualize processes and, thereby, increase comprehension of mechanisms and operations. An additional feature, which seems quite essential in scientific research, is the possibility to alter an ongoing process by adjusting any parameter at any discretionary time and directly achieve tangible results. Regarding the investigation of cell behavior and system interactions, simulations allow a "middle-out" approach, instead of common "top-down" or "bottomup" models, focusing on the cell, as the "basic unit of life" (Walker \& Southgate 2009).

A typical example of the exploitation of the aforementioned simulation features including machine learning tools, is the investigation of evolutionary processes, which are by nature determined by probability and chance and bear a great potential to evolve unpredictable effects (Mertelsmann \& Georg 2016). In sight of the widely accepted hypothesis of carcinogenesis as an evolutionary development (Almendro et al. 2013; Beerenwinkel et al. 2015; Cairns 1975; Klein 2013; Greaves \& Maley 2012; Hanahan \& Weinberg 2011; Merlo et al. 2006; Nowell 1976; Vogelstein et al. 2013; Willyard 2016) it seems reasonable indeed to establish the use of machine learning, simulation models in particular, in cancer research. Recent emphasis on the pivotal role of chance in the development of malignant diseases (Tomasetti \& Vogelstein 2015; Luzzatto \& Pandolfi 2015) even fosters the perception of simulation models as the next logical step in the investigation of carcinogenesis.

"It is the quality of our work which will please God and not the quantity."

- Mahatma Gandhi (Alli 2013)

While current cancer research focuses on data generation, the next major step promises to be a view from a meta-level by exploring data analysis, which, hopefully, will lead to better understanding and novel concepts of cancer prevention, diagnosis, control and therapy.

\subsection{Aims and Objectives}

To address the need for in silico simulation models mentioned above, we want to provide a visually attractive and interactive, and at the same time plausible and 
qualitatively valid simulation model of carcinogenesis and cancer treatment, developed from experimental data. Thereby, the overall objective is to offer a novel tool for basic, clinical and therapeutic research, as well as a teaching tool to make in silico research tangible and applicable to a wide audience.

In the present investigation, the focus lies on the collection and review of relevant data, the formation process of the developed simulations and the first qualitative validation process. In this context, the term validation is used to document the close resemblance of the qualitative prediction of the in silico simulation and real-life biological and clinical data extracted from the relevant literature.

To accomplish this aim, we will address the following research objectives:

1. Identify the essential "Hallmarks of Cancer", based on literature review. The term "Hallmarks of Cancer" was adopted from Hanahan and Weinberg (Hanahan \& Weinberg 2000; Hanahan \& Weinberg 2011) and defines the most fundamental phenotypic characteristics of cancer cells, which are assumed to distinguish the latter from normal cells.

2. Consider literature about the history of cancer research, the hallmarks of cancer, presented by Hanahan and Weinberg, the genetic hallmarks with a focus on gene expression, the principles of evolution, entropy and chance in cancer, the basis of cancer treatment and recent research strategies to develop a new concept of phenotypic cancer hallmarks.

3. Evaluate and synthesize the elaborated hallmark capabilities.

4. Develop mathematical models and algorithms to describe the hallmark characteristics of carcinogenesis.

5. Develop a computational simulation of carcinogenesis based on the algorithms.

6. Test, validate and adapt the algorithms and correlations via repetitive simulation phases.

7. Transfer the insights from the first simulation to a simulation of hematopoiesis.

8. Simulate hematopoietic tissue homeostasis, the establishment of hematopoiesis after stem cell transplantation and leukemogenesis.

9. Reevaluate the "Hallmark Concept" in the light of the simulation results. 


\section{Materials and Methods}

\subsection{Literature Review - Search Strategy}

The first part of the investigation is a narrative literature review with a conceptual analysis (Grant \& Booth 2009). The conduction of the review was partly geared towards the methodological suggestions for scoping studies by Arksey and O'Malley (Arksey \& O'Malley 2005) and additional works (Grant \& Booth 2009; Levac et al. 2010). For the collating and charting process, as well as the purpose of the review, resembled the strategies applied in scoping studies.

The main databases, which we searched, were MEDLINE and PubMed, applying the topics and related search terms and keywords listed in Table 1. Additionally, "Google Scholar" was used as a search engine with a wider spectrum of databases to search the full breadth of available data. Besides, we consulted personal and college libraries, especially the database available via KatalogPlus of Universitätsbibliothek Freiburg. Furthermore, reference lists of pertinent papers were searched via hand search. Additional evidence was acquired by discussions with experts in the fields of interest. There was no temporal limitation, although we favored recent publications, and included both English and German results in the study. Systematic reviews were preferred to achieve the best evidence in sight of the extensive breadth of the topics. The search results were reviewed and evaluated. Data were extracted and sorted by relevance and topic.

\section{Search Keywords}
Cancer History
Hallmarks of Cancer
Phenotypic Plasticity
Cancer Epidemiology
Cancer Stem Cells
Tumor Heterogeneity 


\begin{tabular}{l|ll|}
\hline Cancer Etiology & Biological Evolution & Chance \\
\hline Cancer Research & Entropy & Neoplasia \\
\hline Cancer Evolution & Cancer Entropy & Etc. \\
\hline \multicolumn{2}{l}{ Table 1 Search Terms and Keywords, Examples }
\end{tabular}

\section{Results and Discussion}

\subsection{The War on Cancer Revisited}

\subsubsection{The Concept of Carcinogenesis through the Ages}

Even though it is widely accepted that cancer is a rather modern disease (David \& Zimmerman 2010), the National Cancer Acts mentioned above in the introduction are by far not the earliest efforts of humankind's war on cancer. For a better comprehension of contemporary concepts of carcinogenesis, as well as current achievements of basic science such as research on prevention, diagnosis and treatment of cancer as a first approach, it will be helpful to have a quick glance at the history of cancer.

Early traces of cancer occurrence date back to antiquity. Albeit rather scarce and unprecise, information can be won from ancient inscriptions, archaeological findings, and paleopathology as well as from Egyptian, Greek and Roman written heritage (David \& Zimmerman 2010; Hajdu 2011a). The earliest finding of a human tumor is probably a 35,000-year-old meningioma of the so-called Stetten I. skeletal remains, found in Germany in 1931 (Czarnetzki 1980). In fossil mummies presumed bone cancer was found, most likely osteosarcoma (American Cancer Society 2014). Ancient literature from $3000 \mathrm{BC}$, referred to as the Ewin Smith Papyrus from Egypt, reveals a description of breast cancer. According to this description, there was yet "no treatment" known (Smith \& Breasted 1930). Another Papyrus from 1500 BC, the Papyrus Ebers, refers to "soft-tissue tumors" for the first time. At that time few remedies were known, such as cauterization, surgery or internal and external 
application of salts and arsenic paste and there should not evolve any novel cancer therapies until the $19^{\text {th }}$ century. Also, other cultural groups, such as the Sumerians, Chinese, Indians, Persians or Hebrews, had little therapeutic options to oppose the consuming disease (Hajdu 2011a). It was none less than the Greek Physician Hippocrates (460-375 BC) who replaced the thousand-year-old tradition of superstitions and theological explications by a new concept of cancer origins, the humoral theory. By his belief, cancer had natural roots, more precisely it was induced by an imbalance of body secretions, "humors", like blood, mucus, yellow or black bile. Furthermore, he and his followers observed that cancer rather appeared at an old age and often presented as a crab-like creature growing across a human body. As a result, they coined the terms carcinos (Greek, "crab" ) and carcinoma for malignant tumors, which had by then been recognized in body regions like the skin, mouth, stomach and breast (American Cancer Society 2014; Hajdu 2004). Later the term carcinos was translated into the Latin word cancer by Aulus Celsus (25 BC-50 AD). In his scripture "De Medicina" he depicted both external and visceral types of cancer, among them a couple of parenchymal growths. Despite the notion that early and aggressive surgery could be an effective treatment, it was further observed that cancer was mainly recurrent and fatal in almost every reported case (Hajdu 2004). In the sequel, the Humoral Theory mentioned above was widespread and accepted until it was adopted, concretized and lifted up to an irrefutable doctrine by the Greek citizen of Rome Claudius Galen (130-200 AD). He was convinced that black bile caused incurable ulcerated carcinomas, while yellow initiated curable non-ulcerated cancers (Hajdu 2004). His tenet was taught until the Middle Ages, and it was propagated beyond the Borders of the Western Roman Empire after its fall at the end of the Early Antiquity (476 AD) when the world's intellectual center moved to Constantinople and Baghdad (Hajdu 2011a). About a millennium later, the first one to doubt Galen's theory in public was the French physician Henri de Mondeville (12601320). He linked the occurrence of cancer to prior lesions and established a first classification of cancers regarding anatomic site, size, and penetration depth. Also, he believed in external carcinogens and their ability to enter the human body through gland openings (Hajdu 2011a). In 1315, the first public dissection of two human bodies took place in Bologna, Italy. Since it had been forbidden for religious and superstitious reasons until then, this novelty paved the way to a subsequently deeper understanding of the causality of diseases in general as well as the origins of cancer 
(Hajdu 2011b). In the subsequent, especially during the Renaissance in the $15^{\text {th }}$ century (American Cancer Society 2014), more and more autopsies were performed, mostly of executed criminals, but physicians also began to claim for post-mortem examination of patients who died from illness (Hajdu 2011b). For instance, in 1682, Harvey performed several autopsies, with the result of a better insight into the human circulation of the blood (American Cancer Society 2014).

While surgery, becoming more and more radical, still was the most common treatment of cancer in the $16^{\text {th }}$ century, efforts evolved to cure diseases by systematic therapeutic administration of chemicals. Probably, the most prominent representative of these efforts was Paracelsus (1493-1541), who, administering and examining different drugs, drew the conclusion that every poison could be a remedy at the same time, depending on concentration and dose of the substance (Hajdu 2011b). The most popular of these substances was Arsenic, which was, for instance, widely used by Gabriele Fallopius (1523-1562).

At this time, the first cases of industrial cancer, lung cancers in miners, were reported (Hajdu 2011b). Later, in 1620, Thomas Venner was the first to suspect that tobacco threatened the health and warned of the tobacco danger. It should take another 300 years until the first epidemiologic study finally confirmed the carcinogenicity of tobacco in 1964 (American Cancer Society 2014). Zactus Lusitani (1575-1642) and Nicholas Tulp (1593-1674) presented another presumption. They concluded that cancer was contagious because cases often were accumulated in the same household (American Cancer Society 2014).

In a first attempt to link treatment with research, surgeon Marco Aurelio Severino (1580-1656) compared surgical and pathologic findings (Hajdu 2011b).

Nevertheless, in the 1700s, Stahl and Hoffmann held on to the theory of body fluids and modified it by characterizing cancer as a result of fermenting and degenerating lymph (American Cancer Society 2014). Additional scientific observations followed, e.g. the importance of hormones and viruses in the carcinogenesis in nuns made by Ramazzini in 1713, or the assumed cancerogenic influence of soot on chimney sweepers by Pott in 1775 (16). Deshaies Gendron (1663-1750) interpreted the genesis of cancer as a transformation and continuous growth of glandular, lymphatic, vascular and solid tissues (Hajdu 2011b). After the microscope was invented and had finally got a place in medical research, Morgagni did an essential step towards modern cancer research in 1761 . He was the first to link autopsies of 
deceased patients to pathological findings and created the basis for a pathological and later cell-biology-oriented approach to carcinogenesis (Hajdu 2012a). In the $19^{\text {th }}$ century, breakthrough discoveries followed due to the improvement and the increasing implementation of the microscope. Shortly after Theodor Schwann's publication of his cell theory, in 1838 his mentor Johannes Muller stated that cancer was made up of cells as well. In his opinion, cancer was formed by the consolidation of new cells, which were to grow destructively and scatter by the invasion of blood vessels. Shortly after, "Omnis cellula e cellula" was the closely related pendant of Rudolph Virchow (1821-1902) who detected that all cells were derived from other cells. He considered chronic irritation to cause cancer, which had by then already been proposed by various physicians and surgeons, like John Hill (1716-1775) (Hajdu 2011b), and explained metastasis by spreading of cancer in a fluid-like way (American Cancer Society 2014; Virchow 1859). Even though there was much truth in his findings, the latter was refuted after a short period by Karl Thiersch in the 1860s, delineating metastasis via spreading cells instead of liquids (American Cancer Society 2014). Throughout the $19^{\text {th }}$ century, many believed trauma to be one of the leading causes of cancer (American Cancer Society 2014), e.g. Moritz Wilhelm Hugo Ribbert (1855-1920) suggested that mechanical irritation predisposed cells to turn into cancer cells (Hajdu 2012b). Nevertheless, further concepts were developed. For instance, Julius Cohnheim formulated his idea that malignant tumors evolved from nests of cells that went out of place during the embryonal phase and from cells that could maintain embryonal features. At the same time, anaplasia and asymmetric mitosis were found as likewise characteristics of cancer cells. Both concepts of Cohnheim and Ribbert are still considered valid today (Hajdu 2012b). Shortly after, the surgeon Bilroth (1829-1894) observed that carcinomas and sarcomas had different preferences concerning metastatic spreading, via lymphatics and blood vessels respectively. Thereby he was the first to describe the appearance of the socalled "sentinel lymph node" (Hajdu 2012b). The concept of metastasis was broadened by the seed-and-soil hypothesis set up by Stephen Paget in 1889 , delineating the phenomenon that certain metastatic cells could only settle in certain body sites (DeVita \& Rosenberg 2012). Earlier, in 1879, Samuel D. Gross successfully established the first histogenetic classification of bone sarcomas (Hajdu 2012b). While a steadily rising number of carcinogens was identified in the late 19th century, such as coal tar, paraffin, arsenic and tobacco, another endeavor headed for 
the possible contagious nature of cancer. The high prevalence of malignant diseases in industrial areas and along connected rivers led to this assertion and the subsequent trial to identify probable parasites and viruses which could be responsible for malignancy (Hajdu 2012b). A successful result of this extensive search was the discovery of the parasite Schistosoma Haematobium which was found to be associated with the occurrence of cancer of the bladder by Harrison (1838-1908) (Hajdu 2012b). George T. Beatson (1848-1933) took a different approach and postulated the theory that atrophy of breast tumors could be achieved by a stop of hormonal secretion of the ovary, which led to the first attempts of oophorectomy as a treatment for breast cancer in 1896 (Hajdu 2012b).

At the turn of the century, the diagnosis and treatment of cancer regained momentum by the pioneering serendipity of the discovery of $\mathrm{x}$-rays by Wilhelm $\mathrm{C}$. Roentgen (1845-1923), which soon resulted in diagnostic radiology in 1896 and the beginning of radiotherapy at a later stage (Hajdu 2012b). However, in the subsequent period, it also became apparent that $\mathrm{x}$-rays could cause cancer as well and soon it was registered as a potent carcinogen. The list was augmented by the Rous Sarcoma Virus, a Virus of the RNA-group, which could induce sarcomas in hens and was detected by Peyton Rous in 1911 (American Cancer Society 2014; Hajdu 2012b). At about the same time, David P. von Hansemann (1858-1920) recognized a lack of differentiation in tumor cells and began to divide neoplasms in well- and poorlydifferentiated forms (Hajdu 2012b). In 1913, the first report of accumulation of cancer in a family followed and paved the way to a clearer understanding of heredity of cancer (Hajdu \& Darvishian 2013). One year later Theodor Boveri (1862-1915) made the observation that cancer could be initiated by chromosomal mutation, which laid the foundation to further research on cancer genetics (Boveri 1914). However, before the breakthrough discovery of the cellular transmission of information via DNA instead of proteins by Avery in 1944 and finally, the revealing of the DNA's structure by Watson and Crick in 1953 (DeVita \& Rosenberg 2012), progress was made in pathology, cell biology, etiology, and epidemiology. Technical advances improved lab experiments and were soon able to induce cancer by applying carcinogens (American Cancer Society 2014) or to grow tumor tissue in vitro (Hajdu \& Darvishian 2013). Between 1910 and 1940 several new carcinogens, such as polycyclic carbohydrates, were identified. Classifications for different tumor types were generated, the role of estrogen in the emergence of breast cancer was investigated 
in detail, and various precancerous lesions were identified and linked to malignancy, e.g. ulcer of the stomach (Hajdu \& Darvishian 2013). Outstanding observations were made by Otto H. Warburg (1882-1970), later known as the Warburg Effect. He noticed the importance of oxygen for the maintenance of tissues, the pivotal role of the increase of fermentation in the development of cancer and the fact that malignant cells metabolized more glucose than healthy tissues (Hajdu \& Darvishian 2013). Even though this metabolic alteration provides an 18-fold lower efficiency in the generation of ATP as an energy supplier, certain advantages over normal cellular metabolism have been shown recently, which will be elucidated in detail below (Hanahan \& Weinberg 2011). Of equal importance were the signs of malignancy described by Ewing in 1940, containing a high amount of tumor cells in the state of mitosis, pleomorphic cells, hypervascularity and necrosis (Hajdu \& Darvishian 2013). Furthermore, the major impact of the immune system on the genesis of cancer, or, more explicitly the prevention of cancer, and the influence of advanced age were analyzed (Hajdu \& Darvishian 2013). After the 1940s the vast knowledge about cell changes and carcinogens, chemicals, hormones or viruses, led to a concept of carcinogenesis in 3 steps, "initiation, promotion and latency" (Hajdu \& Vadmal 2013). After achievements in the research on chromosomes as mentioned earlier, the DNA was decoded by Nirenberg and Matthaei in 1961 (DeVita \& Rosenberg 2012). A new age of research dawned with this critical increase of information. It was not to take a long time before the interaction between tumor viruses with their "oncogenes" and cell genes were revealed by Renato Dulbecco (1914-2012). Howard M. Temin (1934-1994) discovered the reverse transcriptase, an enzyme that can transmit information from RNA to DNA (Hajdu \& Vadmal 2013). Further results were the identification of the Philadelphia chromosome in 1960, which plays a pivotal role durin the development of chronic myeloid leukemia (CML), and the description of the first hereditary syndrome, the Lynch-Syndrome, in 1966 (Hajdu \& Vadmal 2013). Soon, the genesis of malignant tumors was linked to the increase in the number of abnormal chromosomes in the cell nucleus, to heritable changes, cell cycle regulation, cell division and control of the genes (Hajdu \& Vadmal 2013). Finally, oncogenes and tumor suppressor genes were identified in the 1970s (American Cancer Society 2014). The latter were identified in 1969 as DNA-binding proteins, that can become oncogenes by chromosomal translocation and point mutation, deletion or amplification of DNA with the result of disruption of the cell cycle control. 
Furthermore, the so-called proto-oncogenes were found, which are retroviruses that can modify genes of normal cells to become genes that cause cancer (Hajdu et al. 2015). Pivotal examples were the $c-M y c$ oncogene in Burkitt Lymphoma or the Her2/neu oncogene in breast carcinoma. Probably, the most important tumorsuppressor gene was discovered in 1979, called p53, also known as "the guardian of the genome" (Lane 1992). It was found to be the most frequently mutated gene in human cancer. It plays a critical role in the development of colorectal carcinoma and certain hereditary syndromes like the Hereditary Non-Polyposis Colorectal Cancer (HNPCC) and Li-Fraumeni-Syndrome (Hajdu et al. 2015). In the same year, it became apparent that cancer cells have proto-oncogenes as well, which are capable of transforming former non-cancer cells into cancer cells and thereby contribute to the development and progression of malignant diseases by genomic changes. Additionally, it was recognized that distinct endogenous growth factors can have an oncogenic influence on the proliferation and differentiation of cells in mitosis (Hajdu et al. 2015).

However, despite all the progress and all the flourishing research cancer mortality in the United States was still higher in the 1960s than in the 1930s. This phenomenon was mainly presumed to be related to the increasing cases of specific cancers, like cancer of the lungs, breast, colon or bladder (Hajdu \& Vadmal 2013). In the sequel, additional genes were identified, e.g. BRCA1 and BRCA2 in breast cancer, as well as further growth factors and their counterparts, such as cytokines like interleukins. A critical system of growth factors was delineated by Judah Folkman (1934-2008), from the discovery of tumor angiogenesis by factors like Vascular Endothelial Growth Factor (VEGF) and prostaglandin, which was considered to be the prerequisite for tissue invasion and metastasis through neovascularization (DeVita \& Rosenberg 2012). The role of angiogenesis in carcinogenesis and cancer progression has recently gained further attention and is still under discussion (Shchors \& Evan 2007). In the late 1960s, the first tests of tumor- and organ-specific immunohistochemistry using antibody coloring were carried out. After a decade, immunotherapy originated with the introduction of strategies exploring a non-specific activation of the immune system (e.g. "Coley's toxin" (Coley 1893)), serotherapy, tumor extracts as vaccines and cytokines. Examples include interferon alpha with its anti-proliferative, proapoptotic, and antiangiogenic effects (Hajdu et al. 2015) or G-CSF in the supportive therapy of neutropenia (Gabrilove, Janice $L$ et al. 1988). More recently, 
strategies allowing to specifically, or at least predominantly, target cancer cells by monoclonal antibodies and small molecules have become one of the major modalities in clinical cancer therapy (Marks \& Mertelsmann 2016).

A different approach was the research on prevention and early detection of malignancy, which was widely accepted regarding screening tests after the 1970s. One of its pioneers was Papanicolaou who invented a smear screening test for cervical epithelial dysplasia in 1976. At a later time, the incorporation of mammography screening resulted in a reduction in mortality due to breast cancer of about $30 \%$. In the beginning, it was presumed, that screening for precancerous lesions and early detection of cancer was the most efficient way to fight the disease. Besides it was asserted that therapy achieved the best results when the tumors were detected at an early stage of growth. However, today this assertion is rather controversial (Hajdu et al. 2015). The careful search for the cancer genome went on, so that by 1983,3844 various chromosomal aberrations had been described in association with human cancer. Genetic instability, meaning the accumulation of cancerous karyotypic changes, was soon identified to play a crucial role in the development and progress of cancer. The same evidence arose concerning the role of apoptosis, describing the programmed cell death, which is typically launched by hypoxia or DNA damage, as a natural protection from misguided cell growth. So, in cancer cells, low numbers of apoptotic cells were found because of the loss of proapoptotic signals, which led to cancer cell growth.

Finally, after the 1980 s, cancer mortality rates began to decline. However, while the incidence of tumors, such as lung or breast cancer, decreased, various lymphoproliferative diseases like multiple myeloma and non-Hodgkin lymphoma, among others, increased. It was not until the 1990s, that a general decline in cancer mortality was reported for the first time (Hajdu et al. 2015). Subsequently, declining incidence of cancer was reported in 1995, albeit rather in men (DeVita \& Rosenberg 2012). About the same time, the association between regular exercise and reduced risk of cancer was demonstrated (DeVita \& Rosenberg 2012). A breakthrough in cancer research during the $21^{\text {st }}$ century was the concept of "targeted therapy", i.e. the search for drugs targeting cancer-specific or associated molecules. One example was the implementation of Imatinib as a Targeted Therapy paired with genomic information by Druker et al. in 2006 (Druker et al. 2006) with stunning success in the treatment of CML (DeVita \& Rosenberg 2012; Berger et al. 2014). 


\subsubsection{The Hallmarks of Cancer (Hanahan and Weinberg)}

The "Hallmarks of Cancer" applied in the following simulations are mainly based on the eight "Hallmarks" and two "Enabling Characteristics" described by Hanahan and Weinberg, with the intention to rationalize the complex process of multistep development of human cancer (Hanahan \& Weinberg 2000; Hanahan \& Weinberg 2011). In their review from 2011, they distinguish between six previously described biological abilities, including "Sustaining Proliferative Signaling", "Evading Growth Suppressors", "Resisting Cell Death", "Enabling Replicative Immortality", "Inducing Angiogenesis" and "Activating Invasion and Metastasis" (Hanahan \& Weinberg 2000), two "Emerging Hallmarks", "Reprogramming Energy Metabolism" and "Evading Immune Destruction", and two "Enabling Characteristics", such as "Genome Instability and Mutation" and "Tumor-Promoting Inflammation" (Hanahan \& Weinberg 2011). Below, the focus will lie in their results from 2011 , as they include a critical review of the results from 2000 , which elucidate the cellular and molecular pathways considered to be the essential steps in carcinogenesis.

\subsubsection{Hallmark Capabilities}

\subsection{Sustaining Proliferative Signaling}

Probably one of the most critical characteristics of a cancer cell is the ability to sustain permanent cell proliferation. In homeostasis, growth-promoting signals and related negative-feedback mechanisms strictly control cell growth. Thereby these growth factors are presumed to be secreted in a paracrine way, by adjacent tissue cells. According to the current perception, they bind cell-surface-receptors with intracellular tyrosine kinase domains, which then emit intracellular signals via various signaling pathways resulting in the regulation of the cell cycle.

Cancer cells, in contrast, lose this kind of cell growth and proliferation control and sustain proliferative signaling in multiple ways.

a) Cancer cells are enabled to produce their growth factors and related receptors and thereby allow autocrine proliferative stimulation.

b) They can stimulate normal cells in the tumor-associated stroma to provide growth factors by signal emission. 
c) Cancer cells can turn hyper-responsive towards proliferative signaling as a result of elevated levels of cell-surface-receptors.

d) Structural alterations in cell-surface-receptors can foster ligand-independent activity.

e) Fundamental activation of components of signaling pathways downstream of the receptors can make the system independent of growth factors by avoiding the need for stimulation. Examples are enzymes such as the MAP-Kinase, PI3-Kinase, and RAS (Hanahan \& Weinberg 2011).

\subsection{Evading Growth Suppressors}

A comparable effect is achieved by a different alteration, the capacity to evade growth suppressors. Growth suppressors normally control cell proliferation. Crucial pathways are related to tumor suppressor genes, so-called gatekeeper genes, such as RB or TP53. Tumor suppressor genes are responsible for the detection and evaluation of cell damage, levels of growth-promoting signals or the supply and lack of cell nutrients, which then result in further proliferation or induction of the apoptosis cascade. Another pathway is the abrogation of cell-to-cell contact inhibition mechanisms by alterations of genes like NF2 or LKB1. Also, the antiproliferative effects of TGF-beta are often evaded by cancer cells and are, in contrast, observed to induce the epithelial-to-mesenchymal transition (EMT), which is highly associated with high-grade malignancy (Hanahan \& Weinberg 2011).

\subsection{Resisting Cell Death}

Apoptosis, the controlled form of cell death, is induced as a result of physiologic stress, e.g. imbalances due to increased oncogene signaling and DNA damage. Both upstream regulators and downstream effectors contribute to this process. The upstream regulators can be divided into two circuits, an extrinsic and an intrinsic one. Both of these circuits end up activating normally latent proteases, like caspase 8 and 9, which initiates a whole cascade of proteolysis. As a result, the cell dissolves progressively and is finally eliminated by neighboring cells and phagocytes. The induction of apoptosis via the cascade of signals mentioned above is regulated by pro- and anti-apoptotic members of the Bcl-2-family of regulatory proteins. 
Thereby, $\mathrm{BCl}-2$ (and its relatives) have an anti-apoptotic effect by binding to and suppressing the normally pro-apoptotic proteins Bax and Bak. The proteins of the $B C l-2$ family have up to four homolog domains $(B H 1-B H 4)$ known to play a crucial functional role. Thereby, a subgroup of proteins, which only share the domain $\mathrm{BH} 3$ (BH3-only proteins) has been found to be fundamental for promoting apoptosis. For instance, sensors like TP53 induce apoptosis by upregulating Noxa and Puma, BH3only-proteins, or insufficient signaling of survival factors like I-3 or insulin-like growth factor 1/2, can trigger apoptosis via activation of $B H 3$-only protein Bim.

In cancer cells, several alterations are responsible for the evasion of apoptosis. Most frequently, TP53 is lost. Furthermore, they can upregulate the expression of antiapoptotic regulators like $\mathrm{BCl}-2$ or $\mathrm{BCl}-\mathrm{xl}$ or of survival signals, downregulate the proapoptotic factors Bax, Bim and Puma or short-circuit extrinsic ligand-induced apoptosis cascades.

Although necrosis was long assumed to be the uncontrolled counterpart of apoptosis, it is recently observed to be governed by a genetic control in certain circumstances. Necrotic tissues can secrete pro-inflammatory signals, which help to recruit inflammatory cells. The recruited immune cells can then promote tumor growth by inducing angiogenesis, cell proliferation and invasiveness (which will be explained in detail below). Also, necrotic cells can directly trigger cell proliferation of adjacent cells by secretion of regulatory factors like $\|-1 \alpha$.

Another mechanism, which is potentially tumor-promoting, is autophagy. It is a physiologic cell response to certain stress conditions, mainly, nutrient deficiency, to allow adjustment of cellular energy metabolism and biosynthesis. As a consequence, autophagy can both keep the cell from accumulating DNA damage and subsequent tumorigenesis and promote tumor growth at a later stage by the protection of the cell by shrinking it to a state of reversible dormancy. Autophagy seems to play a fundamental role in treatment response, recurrence, and metastasis (Hanahan \& Weinberg 2011).

\subsection{Enabling Replicative Immortality}

Normal cells can go through a limited number of growth-and-division cell cycles, associated with two proliferation barriers, senescence, and crisis, whereas crisis follows senescence. Under several circumstances, cells can get immortalized. In 
normal cells, the telomeres, which are multiple tandem hexanucleotide repeats at the ends of the chromosomes, protect these ends from instability and subsequent damage from end-to-end fusions, which result in non-viable karyotypes. Over time, the length of the telomeres shortens progressively with each cell division, decreasing the ability of DNA protection. Therefore, the length of telomeric DNA strictly correlates with the number of possible successive cell division cycles. In over $90 \%$ of immortalized cells, a specialized DNA-polymerase, telomerase, which is absent in normal cells, is expressed and adds telomere repeat segments to the shrinking ends of telomeric DNA. As suppression of telomerase activity has resulted in telomere shortening and activation of senescence and crisis with subsequent cell death, one can assume that the presence of this activity highly correlates with the resistance to cell death via senescence and apoptosis. To reach this resistance, cancer cells exhibit two cell mechanisms. First, they have the capability to upregulate the expression of telomerase, with the consequences depicted above, and to make use of alternative recombination-based telomere maintenance mechanism. Under normal conditions, an incipient neoplasia is eliminated because of the exhaustion of possible cell divisions and unbalanced elevated oncogene signaling or telomere shortening trigger the induction of senescence, both protective mechanisms against cancer.

However, in the case of delayed acquisition of telomerase, telomere shortening can also foster tumor progression. Because of subcritical telomere shortening, as elucidated above, early cancer cells are put into a state of senescence and crisis. If TP53 is additionally mutated, the shortened telomeres cannot be detected by the cell-death machinery, which results in increased DNA instability and consequently elevated mutation rates. Combined with the following expression of telomerase, which amplifies telomeric DNA including existing DNA damages, the aberrant karyotype is turned immortal. Apart from this mechanism, telomerase is assumed to have additional fostering effects on cell proliferation through several pathways related to the protein subunit TERT. They can result in the promotion of cell proliferation or resistance to apoptosis and are involved in the DNA repair system, as well as the activity of the RNA-dependent RNA-Polymerase, which will not be described in detail here (Hanahan \& Weinberg 2011). 


\subsection{Inducing Angiogenesis}

The increasing need for oxygen and nutrition, as well as the opportunity to eliminate metabolic waste and carbon dioxide of a growing tumor mass, is mainly addressed by neovasculature, originated by angiogenesis. In normal tissue, angiogenesis is transiently activated in wound healing and the female reproductive cycle. In contrast, in cells of almost every tumor type the angiogenic switch causes a permanent activation of angiogenesis, already at early stages of tumor growth like the premalignant phase with microscopic lesions. Counterbalancing inducers and inhibitors, such as VEGF-A (growth factor-A) and Thrombospondin-1 (TSP-1) regulate this angiogenic switch. As signaling products, they bind to either stimulatory or inhibitory cell-surface receptors. While VEGF has a proliferating effect on the vasculature and can be upregulated by hypoxia and oncogenic signaling, TSP-1 triggers suppressive signals which antagonize pro-angiogenic signals. Also, fibroblast growth factors, FGF, can be upregulated to sustain angiogenesis.

In general, tumors can be hypo- and hypervascularized, whereby the tumorous vasculature is frequently altered, for example, it is convoluted and branched and presents erratic blood flow. Dynamically, it has been observed that angiogenesis starts with the aforementioned angiogenic switch and is followed by ongoing neovascularization of varying intensity. The switching mechanism described above can be triggered by both oncogenes, such as Ras and $M y c$, which can upregulate the expression of angiogenic factors, or by immune inflammatory cells. The latter include peritumoral inflammatory cells from the innate immune system, like macrophages and neutrophils. Apart from tripping the angiogenic switch and sustaining angiogenesis, they are capable of protecting the blood vessels from targeted drugs. Additionally, "vascular progenitor cells" have been found to migrate into tumorous tissue and be intercalated as pericytes or endothelial cells (Hanahan \& Weinberg 2011).

\subsection{Activating Invasion and Metastasis}

The process of Metastasis can be described as an "Invasion-Metastasis-Cascade", including local invasion, intravasation, transit through lymph and blood vessels, extravasation into the parenchyma of distant tissues and colonization of micro- and macrometastases. To keep it more simple, one can distinguish between a phase of 
invasion/dissemination and colonization. In general terms, the diffusion of cancer cells can be explained by the down-regulation of cell-to-cell and cell-to-extracellular matrix (ECM) adhesion molecules, such as E-cadherin, and the upregulation of molecules normally present in embryogenic and inflammatory processes, associated with cell migration, such as $\mathrm{N}$-cadherin, originated by altered gene expression. Additionally, the role of the developmental regulatory program of epithelial-tomesenchymal transition (EMT) has been stressed, since the transformation of epithelial to mesenchymal cells comes along with the acquisition of the capability to invade, resist apoptosis and finally disseminate. This phenomenon is physiologically observed during embryogenesis and wound healing and can be activated either transiently or permanently. While the core of a tumor can still be distinct, EMT can proceed at the margin of the lesion. On a molecular level, transcriptional factors like Snail, Slug, Twist and Zeb 1/2 overexpressed in several cancer types have been identified to contribute to programming invasion, and even trigger metastasis when ectopically expressed. In particular, they are responsible for the loss of adherence junctions, the transition from epithelial to mesenchymal fibroblastic morphology, the upregulation of the expression of matrix-degrading enzymes, increased cell motility and resistance to apoptosis, as well as a direct inhibition of E-cadherin gene expression. The expression of the transcription factors above can not only be tripped by additional mutated genes, but also by adjacent tumor-associated stromal cells and crosstalk between cancer cells and the stroma surrounding the tumor. For instance, mesenchymal stem cells (MSCs) react to signals from cancer cells by secreting CCL5/Rantes, which can then trigger invasiveness in cancer cells.

Furthermore, cancer cells can emit $I L-4$, which stimulates macrophages at the periphery to secrete matrix-degrading enzymes, such as metalloproteases and cysteine cathepsin proteases, which promote local invasion by cancer cells. Another two suggested modes of invasion shall be mentioned here, without being explained in detail. First, "Collective Invasion" is considered to be cancer cell nodules, that move into adjacent tissues in high quantities. Second, "Amoeboid Invasion" is asserted as the migration of individual cancer cells with morphological plasticity through existing spaces in the ECM.

The second part of the metastasis cascade, the colonization, somehow requires the potential reversibility of invasion and EMT. To describe the necessary cell plasticity, which allows a cell to revert to a non-invasive state in a novel environment, the term 
Mesenchymal-to-Epithelial-Transition (MET) was coined. Thereby, colonization does not necessarily seem to be linked to previous physical dissemination. Therefore, micrometastases can exist without developing into visible metastatic lesions. A possible explanation could be the release of systemic growth suppressor factors by the primary tumor, which transfers the micrometastases into a state of dormancy since the explosive growth of metastatic lesions has been observed after resection of the primary tumor. Moreover, nutrient starvation can also end up in dormancy as a result of autophagy. Nevertheless, proliferation can be reactivated when the tissue microenvironment changes. Furthermore, dormancy might be associated with antigrowth signals in the ECM of normal tissues or the surveillance by the immune system. Another hypothesis states that micrometastases lack other fundamental hallmark capabilities, such as the induction of angiogenesis. In any case, it has been observed that certain tissues may be more hospitable to micrometastases than others, by providing or establishing a permissive tumor microenvironment. The time of dissemination and invasion also shows a huge variability, ranging from non-invasive premalignant lesions to full-blown highly malignant tumors. Thereby, the ability to colonize may either be acquired in the primary tumor already or as a result of a mounting selective pressure on the already disseminated cancer cells. Even colonized metastatic cells are assumed to be capable of ongoing dissemination, including tumor-reseeding, also called reverse migration. Therefore, gene expression and resulting phenotypes of primary tumors may also depend on metastatic cells.

\subsection{Reprogramming Energy Metabolism}

To the advantage of cell growth and proliferation, cancer cells have been observed to present the capability of adjusting cellular energy metabolism. Normally, under aerobic conditions, glucose is processed to pyruvate via glycolysis in the cytosol and finally to carbon dioxide in the mitochondria. Under anaerobic conditions, glycolysis is favored indeed, and only little pyruvate is transferred to the mitochondria, where processing into carbon dioxide consumes a considerable amount of oxygen. Cancer cells, in contrast, have shown an aberrant energy metabolism, primarily asserted by Warburg, which is now termed "aerobic glycolysis". As this term suggests, these cells favor glycolysis even under aerobic conditions, even though it exhibits approximately 18-fold lower efficiency in ATP production. Cancer cells have frequently shown an 
increased glucose uptake and utilization, which is why they are assumed to address this lack of efficiency with an increasing glucose import into the cytoplasm via upregulation of glucose transporters, especially GLUT1.

The alteration of the energy metabolism is also associated with mutated oncogenes, such as Ras and Myc, and tumor suppressor genes, like TP53. Transcription factors, HIF1 $\alpha$ and HIF2 $\alpha$ respectively, upregulate glycolysis, which can be triggered by both Ras and hypoxia. Despite the low efficiency in energy production, the increase of glycolysis provides various advantages for growth and proliferation of cancer cells. It enables the infiltration of intermediates into biosynthetic pathways and fosters the biosynthesis of macromolecules and organelles, both critical prerequisites for the assembly of new cells.

Another phenomenon termed the "Warburg-effect", has been considered crucial to the understanding of tumor growth. Assuming that there are two subpopulations in malignant tumors, they can exploit each other in a symbiotic manner. Whereas one utilizes glucose and emits lactate, the second can utilize the secreted lactate as its primary energy source and conduct it into the citric acid cycle, since it is better oxygenated. On the one hand, this phenomenon might only reflect a normal physiological mechanism of co-option, for instance, observed in muscle cells, or as a result of the fluctuation of oxygen supply in tumor tissues and the related alternated neovascularization. On the other hand, data suggest that gain-of-function mutations in the enzymes Isocitrate Dehydrogenase 1/2 may be of great importance in glioma and other human tumors (Hanahan \& Weinberg 2011).

\subsection{Evading Immune Destruction}

Various observations in human cancers suggest that surveillance by the immune system is crucial for the recognition and elimination of the majority of early neoplastic cells. Consequently, persisting cancer cells are expected to be capable of evading this detection and the subsequent elimination by certain mechanisms. Even though a higher incidence of malignancies has been recognized in immunocompromised patients, the vast majority of these cancers are associated with a viral etiology. Nevertheless, experiments in mice have shown high cancer incidences in mice lacking CD8+ cytotoxic T-lymphocytes (CTLs), CD4+ Th1 Helper T-cells or natural killer cells (NKs), and even more significant when combined. 
These findings suggest that both the innate and the adaptive immune system are responsible for the surveillance, detection, and elimination of tumor growth, which transplantation models in immunodeficient and immunocompetent mice could further emphasize. In human cancer, evidence about the role of the immune system is scarce. However, some findings indicate similarities to the observations in mice experiments. For example, human colon and ovarian cancers with a high-grade infiltration by CTLs and NKs normally are associated with a better prognosis than those lacking this infiltration. Furthermore, development of donor-derived types of cancer, which have not been clinically detected in the donor before, has been noted in immunosuppressed organ transplant recipients. As a consequence, these tumor cells are considered to have been controlled by the donor's immune system before, presumably in a state of dormancy. As mentioned above, patients with chronical immunosuppression do not show higher incidences of non-viral etiology tumors. According to the observations concerning the roles of the innate and the adaptive immune system, one might assume that this phenomenon could be attributed to the fact that such immunodeficiency is primarily associated with a lack of $T$ - and B-cells, which might leave behind a residual potential of surveillance by NKs and the innate immune system.

Several conceivable mechanisms shown by cancer cells to evade the detection and eradication by the immune system have been proposed. Cancer cells are assumed to emit TGF- $\beta$ or other immunosuppressive factors to paralyze infiltrating CTLs and NKs. Another possible process is the suppression of cytotoxic lymphocytes by the recruitment of actively immunosuppressive inflammatory cells, such as Regulatory Tcells (TREGs) and Myeloid-Derived Suppressor Cells (MDSCs).

\subsubsection{Enabling Characteristics}

\subsection{Genome Instability and Mutation}

A feature that enables the evolution of malignant cell populations is that cancer cells frequently show increased mutation rates, which can be attributed both to increasing sensitivity towards mutagenic agents and insufficient genomic maintenance mechanisms. Both pathways contribute to the accumulation of mutations. A crucial role in genome maintenance plays the TP53 mentioned above. Nevertheless, a range of "caretakers of the genome" have been identified and are known to be 
responsible for the detection of DNA damage and the subsequent activation of the required repair mechanism, the DNA repair itself and the inhibition of mutagenic molecules. These caretaker genes mainly behave like tumor suppressor genes. During tumor progression, functions critical to genome maintenance can diminish through genetic and epigenetic alterations.

An additional cause of genomic instability is the loss of telomeric DNA, which results in karyotypic instability and expansion and deletion of chromosomal sections. These mechanisms finally lead to various patterns of DNA alterations in distinct tumor types, whereas the majority results in defects in genome maintenance and repair machinery and destabilization of gene copy number and nucleotide sequence (Hanahan \& Weinberg 2011).

\subsection{Tumor-Promoting Inflammation}

Immune cells, both of the innate and the adaptive immune system, are always observed in malignant tumors. Densities range from discreet infiltrations to heavy inflammations. Primarily, this immune response can be seen as an attempt of the organism to eliminate tumor cells and prevent the evolution of a full-grown tumor mass. At the same time, it represents an increasing selective pressure on the tumor to develop mechanisms to evade destruction by the immune system. Nevertheless, the participation of immune cells shows promotion of tumorigenesis and tumor progression in a paradoxical and surprising way by various mechanisms, each assisting incipient neoplasias with the acquisition of hallmark characteristics. Inflammation present at very early stages of tumorigenesis confirms this assertion. Tumor fostering can be achieved by the provision of bioactive molecules to the tumor microenvironment, such as growth factors sustaining proliferative signaling, survival factors limiting cell death, proangiogenic extracellular matrix-modifying enzymes enabling angiogenesis, invasion, and metastasis, signals inducing EMT or actively mutagenic chemicals of reactive oxygen species (Hanahan \& Weinberg 2011). 


\subsubsection{The Genetic Hallmarks of Cancer - Gene Expression Hallmarks}

To give a broad overview of the essential cancer cell hallmarks, the impact of the cancer genome, apparently, cannot be overlooked. The focus of genomic research has lain on pure genetic mutations and still gets most of the attention, for instance, in whole-genome-sequencing (Hayes \& Kim 2015) or the intensive search for so-called driver mutations and driver genes (Vogelstein \& Kinzler 2015). However, epigenetic

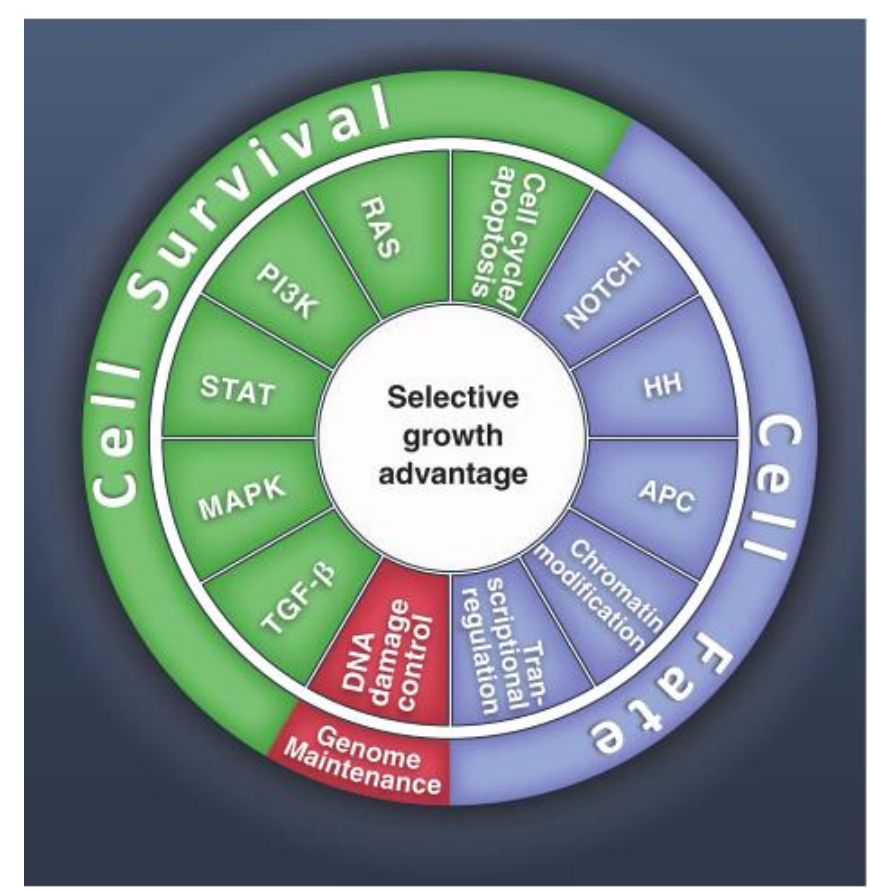

Figure 2 Core Cellular Pathways, Cancer Genome Landscapes, Vogelstein et al., 2013 alterations have indeed been explored and were found to be important in the process of carcinogenesis as well. For example, DNA-methylation has been observed to play a pivotal role in the development of several cancer types (De Carvalho et al. 2012; Muntean \& Hess 2009). In 2013, Vogelstein et al. provided the cluster shown in Figure 2 with the intention to include genetic and epigenetic alterations in the concept of carcinogenesis and allocated them to three different cellular pathways, which are

assumed to be associated with the development of malignant tumors. According to them, the three most essential pathways are "Cell Fate" (NOTCH, HH, APC, Chromatin Modification, Transcriptional Regulation), "Cell Survival" (TGF- $\beta$, MAPK, STAT, PI3K, RAS, cell cycle/apoptosis) and "Genome Maintenance" (DNA damage control) (Vogelstein et al. 2013).

Further, findings indicate that genetic and epigenetic alterations do not only contribute to the development of cancer but can, indeed, influence each other. Epigenetic modifications are assumed to be able to increase the mutability of the genome, whereas genetic mutations result in epigenetic changes as well. In the end, both genetic and epigenetic alterations and their interactions contribute to gene expression (You \& Jones 2012). 
As indicated above, we will examine the phenotypic hallmarks of cancer, as phenotypic alterations are the most essential for cellular fate and tissue interactions. Therefore, we will focus on gene expression, instead of genotypic mutations in the following.

Recently, extensive meta-analysis of gene expression and subsequent clustering and mapping of the results by Torrente et al. provided an impressive amount of data. From 40,000 publicly available Affymetrix HG-U133Plus2 arrays, they investigated 20,000 genes in 28,000 samples and established a map of gene expression (Torrente et al. 2016). As a result, they found clusters of genes highly expressed in certain tissue types as well as genes overexpressed in cancer pathways. While previous assumptions could be reflected in the Principal Component Analysis (PCA) (Fig. 3), unexpected outcomes were observed as well. For example, the formation of two distinct clusters of breast cancer, which indicates a yet unexplored division of breast cancer in two different diseases. Concerning the expressed genes, those

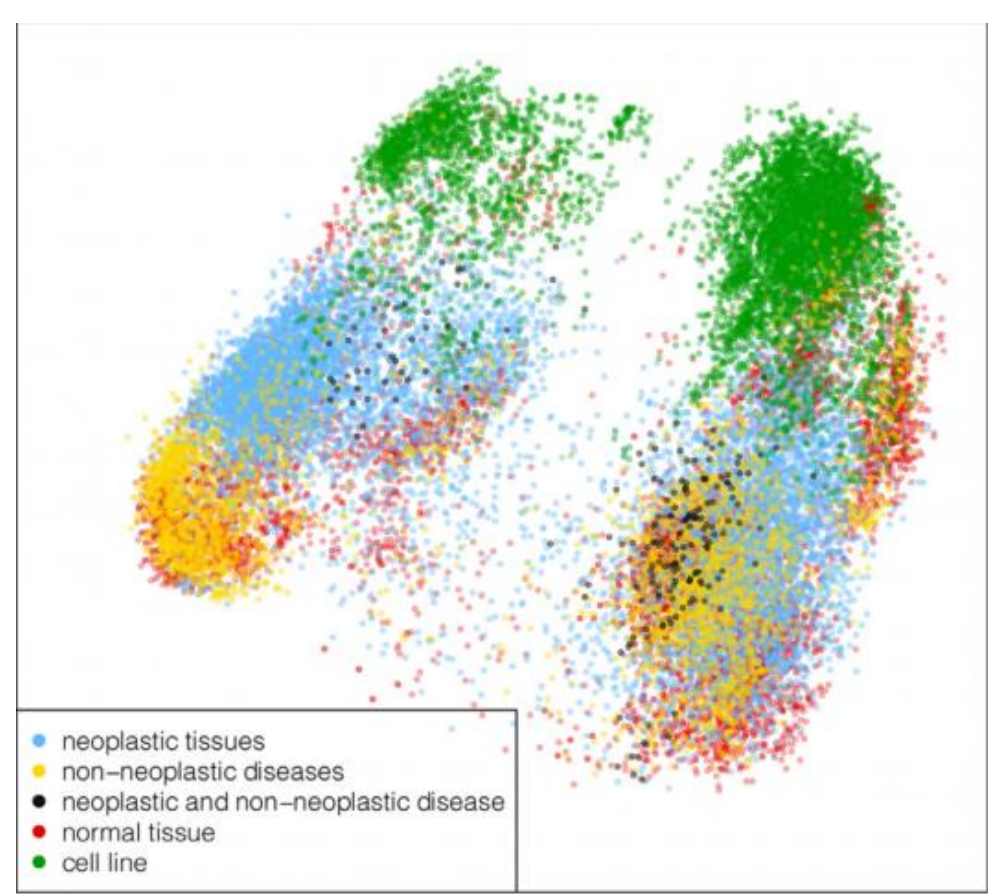

Figure 3 Exemplary PCA of gene expression mapping, Identification of Cancer Related Genes Using a Comprehensive Map of Human Gene Expression, Torrente et al., 2016

already known to be associated with cancer were found as well as novel potential cancer genes. To allow a better overview of the results they suggested a category mapping, which included categories like "Cell Division", "DNA Repair" and "G-protein Coupled Receptor Protein" (Torrente et al. 2016). These classes partly overlap with the hallmarks suggested by Hanahan and Weinberg (Hanahan \& Weinberg 2011), which led us to remap the genes of the 100 probably most relevant probe sets (Fig. 4). 


\begin{tabular}{|c|c|c|c|}
\hline $\operatorname{AATF}(*)$ & AK056098 & ANAPC7 $(* *)$ & ANXA11 $(* *)$ \\
\hline ARNTL $(* *)$ & ASPN $\left({ }^{* *}\right)$ & BLM $\left({ }^{*}\right)$ & C1orf21 (**) \\
\hline CASK $\left({ }^{* *}\right)$ & CBFA2T2 $\left({ }^{* *}\right)$ & $\mathrm{CBX} 2(* *)$ & CD80 $\left({ }^{* *}\right)$ \\
\hline CDCA4 $\left({ }^{* *}\right)$ & $\mathrm{CHP} 1\left({ }^{* *}\right)$ & CHTOP $(* *)$ & $\mathrm{CPSF}^{[1]}$ \\
\hline CSE1L $\left(^{*}\right)$ & $\operatorname{CxCL10}\left({ }^{*}\right)$ & CYB5D2 & DCAF13 $(* *)$ \\
\hline $\operatorname{DDX} 11\left({ }^{* *}\right)$ & DLEU2 $2^{[2]}$ & DNMT1 $(*)$ & DUSP5P1 $\left({ }^{* *}\right)$ \\
\hline EMR2 & FAM122B $\left({ }^{* *}\right)$ & FANCA $\left({ }^{*}\right)$ & FCGR1A $^{[3]}$ \\
\hline FCGR1B $(* *)$ & FDX1 $\left({ }^{* *}\right)$ & FLJ41455 & GABBR $1^{[4]}$ \\
\hline GINS4 $\left({ }^{* *}\right)$ & GMPS $\left({ }^{*}\right)$ & HAUS3 $\left({ }^{* *}\right)$ & HAUS8 $\left({ }^{* *}\right)$ \\
\hline HCG18 & $\operatorname{HELLS}\left({ }^{*}\right)$ & LEF1 $\left({ }^{* *}\right)$ & LOC100506639 \\
\hline $\operatorname{LPCAT} 1(* *)$ & MAP3K12 $(* *)$ & MATR3 $^{[6]}$ & MIR1204 $4^{[7]}$ \\
\hline MMP24-AS1 & MMP9 $\left({ }^{*}\right)$ & MTBP $(* *)$ & $\operatorname{NCOA6}\left({ }^{* *}\right)$ \\
\hline $\operatorname{NCOR} 1\left(^{* *}\right)$ & $\mathrm{NR} 2 \mathrm{C} 1\left(^{* *}\right)$ & NR2C2AP $(* *)$ & NR3C2 $(*)$ \\
\hline $\operatorname{NSMCE2}\left({ }^{* *}\right)$ & NSUN2 $\left({ }^{* *}\right)$ & NUDT1 $\left({ }^{* *}\right)$ & PARP9 $(* *)$ \\
\hline PDS5A $(* *)$ & POLQ $\left({ }^{* *}\right)$ & PPP2CB $(* *)$ & PRDM13 $(* *)$ \\
\hline PTP4A3 $(* *)$ & RBL1 $\left({ }^{* *}\right)$ & RFX5 & RGS1 $\left({ }^{* *}\right)$ \\
\hline RGS16 $\left(*^{*}\right)$ & RNPS1 $\left({ }^{* *}\right)$ & RP11-353N14.2 & RP11-93209.10 \\
\hline RPS15A $\left({ }^{* *}\right)$ & RPS6KB1 $\left({ }^{* *}\right)$ & S100PBP $(*)$ & SALL4 $\left({ }^{* *}\right)$ \\
\hline SMOC2 $\left(*^{*}\right)$ & SNORA72 $\left({ }^{* *}\right)$ & STX12 $\left({ }^{* *}\right)$ & TDO2 $\left({ }^{* *}\right)$ \\
\hline THOC2 $(* *)$ & TIAL1 $(* *)$ & TMEM194A $\left({ }^{* *}\right)$ & TMEM246 $(* *)$ \\
\hline TREM2 $\left({ }^{* *}\right)$ & U2SURP $\left({ }^{* *}\right)$ & USP32 $\left(^{*}\right)$ & VPS13D \\
\hline VWA1 $\left({ }^{* *}\right)$ & ZDHHC2 $\left({ }^{* *}\right)$ & ZHX1-C8orf76 & ZNF174 $\left({ }^{* *}\right)$ \\
\hline ZNF680 & ZNF692 $\left({ }^{* *}\right)$ & ZNF7 $\left({ }^{* *}\right)$ & \\
\hline
\end{tabular}

[1] CPSF1 $\left(^{* *}\right) / / / \operatorname{MIR} 1234\left({ }^{* *}\right) / / / \operatorname{MIR} 6849$ /// MIR939 (**)

[2] DLEU2 $\left({ }^{* *}\right) / / / \operatorname{MIR} 15 A\left({ }^{* *}\right)$

[3] FCGR1A $\left(^{* *}\right) / / /$ FCGR1B $\left({ }^{* *}\right) / / /$ FCGR1C

[4] GABBR1 $\left({ }^{* *}\right) / / / \mathrm{UBD}\left({ }^{*}\right)$

${ }^{[5]}$ LOC100506639 /// ZNF131 (**)

${ }^{[6]} \operatorname{MATR} 3\left({ }^{* *}\right) / / / \mathrm{SNHG} 4\left({ }^{* *}\right)$

${ }^{[7]}$ MIR1204 /// PVT1 $\left({ }^{*}\right)$

Figure 4 List of genes mapped to by the top 100 probesets, Identification of Cancer Related Genes Using a Comprehensive Map of Human Gene Expression, Torrente et al., 2016

In what follows the most frequently expressed genes are listed and explained for better understanding (Tab. 2):

\begin{tabular}{lll}
\hline Gene & Pathway \\
\hline DDX11 & $\begin{array}{l}\text { cell proliferation, chromosome transmission fidelity and genome } \\
\text { stability } \\
\text { subfamily of G-protein coupled receptors }\end{array}$ \\
\hline EMR2 & $\begin{array}{l}\text { enhance cell proliferation, and overexpression of this gene has } \\
\text { been implicated in tumor metastasis. }\end{array}$ \\
\hline TRE4A3 $\left(^{* *}\right.$ The encoded protein functions in immune response and may be \\
involved in chronic inflammation by triggering the production of \\
constitutive inflammatory cytokines. \\
ASPN & $\begin{array}{l}\text { The encoded protein may regulate chondrogenesis by inhibiting } \\
\text { transforming growth factor-beta 1-induced gene expression in } \\
\text { cartilage. This protein also binds collagen and calcium and may } \\
\text { induce collagen mineralization. Polymorphisms in the aspartic acid }\end{array}$
\end{tabular}




repeat region of this gene are associated with a susceptibility to
osteoarthritis, a
MAP3K12 (Mitogen-Activated Protein Kinase Kinase Kinase 12) is
a Protein Coding gene. Among its related pathways are MAPK
signaling pathway and TGF-Beta Pathway. GO annotations
related to this gene include protein homodimerization activity and
protein kinase activity. An important paralog of this gene is KSR1.
Proteins of the matrix metalloproteinase (MMP) family are involved
in the breakdown of extracellular matrix in normal physiological
processes, such as embryonic development, reproduction, and
tissue remodeling, as well as in disease processes, such as
arthritis and metastasis.
This gene encodes a member of the ribosomal S6 kinase family of
serine/threonine kinases. The encoded protein responds to mTOR
(mammalian target of rapamycin) signaling to promote protein
synthesis, cell growth, and cell proliferation. Activity of this gene
has been associated with human cancer.
The Bloom syndrome gene product is related to the RecQ subset
of DExH box-containing DNA helicases and has both DNA-
stimulated ATPase and ATP-dependent DNA helicase activities.
Mutations causing Bloom syndrome delete or alter helicase motifs
and may disable the 3'-5' helicase activity. The normal protein may
act to suppress inappropriate recombination.
This gene encodes a transcription factor belonging to a family of
proteins that share homology with the high mobility group protein-
1. The protein encoded by this gene can bind to a functionally
important site in the T-cell receptor-alpha enhancer, thereby
conferring maximal enhancer activity. This transcription factor is
involved in the Wnt signaling pathway




\begin{tabular}{|c|c|}
\hline NUDT1 & $\begin{array}{l}\text { Misincorporation of oxidized nucleoside triphosphates into } \\
\text { DNA/RNA during replication and transcription can cause mutations } \\
\text { that may result in carcinogenesis or neurodegeneration. }\end{array}$ \\
\hline ANXA11 & $\begin{array}{l}\text { This gene encodes a member of the annexin family, a group of } \\
\text { calcium-dependent phospholipid-binding proteins. Annexins have } \\
\text { unique N-terminal domains and conserved C-terminal domains, } \\
\text { which contain calcium-dependent phospholipid-binding sites. The } \\
\text { encoded protein is a } 56-k D \text { antigen recognized by sera from } \\
\text { patients with various autoimmune diseases }\end{array}$ \\
\hline RGS1 & $\begin{array}{l}\text { RGS1 (Regulator Of G-Protein Signaling 1) is a Protein Coding } \\
\text { gene. Among its related pathways are G-protein activation and } \\
\text { Activation of cAMP-Dependent PKA. GO annotations related to } \\
\text { this gene include GTPase activator activity and calmodulin } \\
\text { binding. }\end{array}$ \\
\hline TDO2 & $\begin{array}{l}\text { This gene encodes a heme enzyme that plays a critical role in } \\
\text { tryptophan metabolism by catalyzing the first and rate-limiting step } \\
\text { of the kynurenine pathway. Increased activity of the encoded } \\
\text { protein and subsequent kynurenine production may also play a } \\
\text { role in cancer through the suppression of antitumor immune } \\
\text { responses, and single nucleotide polymorphisms in this gene may } \\
\text { be associated with autism. }\end{array}$ \\
\hline
\end{tabular}

\subsubsection{Principles of Evolution and Entropy - Cancer as an evolutionary disease}

\subsubsection{Evolution}

\subsection{History and Principles of Biological Evolution}

The concept of biological evolution was developed and modified throughout the ages, beginning in the $19^{\text {th }}$ century and resulting in what we call today the modern theory of evolution or the evolutionary synthesis. In this development, one can define three stages: Darwinism, Neo-Darwinism, and the Synthetic Theory. 
The notion of the evolution of organisms by continuous transformation dated back to Greek philosophers and was further taken up by several authors from the $18^{\text {th }}$ and $19^{\text {th }}$ century. While Lamarck postulated the concept of "soft inheritance", the inheritance of acquired characteristics, it was not until 1858, that Darwin developed the idea of natural selection playing a pivotal role in the descent of organisms and their populations. He based his hypothesis on five critical observations: that nature produced more descendants than their environment would allow, that there was a vast amount of intraspecific variants in most populations, that there evolved a struggle for survival by means of a competition for limited resources, that one could note heritable modifications in the offspring of some organisms and that new species occurred. In his book "The Origin of Species" Darwin defined five fundamental concepts: the evolutionary process, the theory of common ancestry, the idea of gradualism, the multiplication of species and the phenomenon of natural selection. He considered every organism to have derived from a common ancestor, via permanent genomic and morphological transformations mainly driven by natural selection. In 1889, Wallace further developed the concept of gradualist evolution and natural selection and finally coined the term "Darwinism".

[Back in the $19^{\text {th }}$ century intermediate forms of species were mostly unrecognized, which stood in contrast to the thesis of gradualism. However, novel discoveries of several lineages of beings should diminish doubts and the contrary idea of punctuated equilibrium. The concept of common ancestry was further developed and is now appreciated as the "universal phylogenetic tree of life".] The following period was named "Neo-Darwinism" by Romanes in 1895. Researchers took up the Darwinian concept of organismic evolution and natural selection, shedding light on the conversion and diversification of species and the responsible processes of evolutionary development. An outstanding figure was Weismann, who refuted the Lamarckian perception of the inheritance of acquired characteristics by experimental evidence in 1892, and considered the role of sexual recombination as crucial for the creation of freshly variable populations of organisms in every generation.

The following Post-Neo-Darwinian period, between 1937 and 1950, yielded both controversial concepts as well as the cradle of the modern theory of evolutionary synthesis. As the different concepts of Creationism, Lamarckism, Orthogenesis, and Transmutationism all proved untenable over time, they will not be discussed here. 
The focus shall rather lie on the principles and the fundamental assertions of the modern evolutionary synthetic theory of biological evolution. The difference between former theories and the new one was the fact that the latter was based on genetics, systematics, and paleontology instead of the mere observation of populations. Six researchers, the naturalists Dobzhansky and Mayr, the zoologists Huxley and Rensch, the paleontologist Simpson and the botanist Stebbins, perpetuated their discoveries in six books building the fundament of the contemporary understanding of evolution. Although each of them represented an individual focus, their postulates can be summarized in six basic principles:

1) The observed items of evolution are populations of eukaryotic organisms and species. Species are defined as interbreeding communities that are isolated from other communities concerning reproduction.

2) Genetic recombination during sexual reproduction and random mutations in the hereditary process cause the variability of genotypes in a population.

3) The average of a population is shaped and changed to a better-adapted novel phenotype by directional natural selection. It mainly affects the phenotypic evolution as a result of a growing selective pressure of an altered environment. A second force is the random genetic drift in rather small populations.

4) The process of speciation is defined as the stage when two novel phenotypes become incapable of interbreeding. One can distinguish between allopatric speciation (divergent evolution of geographically isolated populations) and sympatric speciation (convergent or divergent evolution of populations in the same geographical location).

5) The concept of Gradualism mentioned above postulates that evolution takes place by small and slow changes, which are maintained at each evolutionary step and lead to higher species by the accumulation of these changes over time.

6) The so-called Macroevolution is a gradual process, which can be seen as the "extrapolation of microevolution".

The vast majority of these principles are still considered valid today. Various experiments and studies have stressed their validity in the last decades. At the same time, the main controversy persists in the question of gradualism, since punctuated 
events and varying rates of phylogenetic development of populations could have been shown, and the investigation of the environmental impact on transformation and diversification is still of critical interest.

More recent discoveries are the so-called Phenotypic Plasticity and the Mechanisms of Epigenetics. The former describes the broad range of variability of phenotypic expression of identical genotypes correlating with the environmental setting of an organism. Thereby, one can assume that selective pressure acts rather on the phenotype than directly on the genotype or at least on the whole organism.

Epigenetic processes represent pivotal mechanisms for this phenotypic variability. Epigenetic changes influence the expression of certain genes by i.e. promotion or silencing of genes and seem not to depend directly on the gene products and rather on the environmental pressure. Further, it was shown that the majority of heritable and mutable genes and their products were transformed mainly by random genetic drift and mutation, rather than by positive natural selection. As positive selection seems to play a crucial role in the evolution of proteins in fruit flies and other species, one can suspect the importance of natural selection on a molecular basis (Kutschera \& Niklas 2004).

\subsection{Cancer is an evolutionary disease}

At the current stage of the research, it has become consensus that the development of cancer follows the fundamental principles of somatic evolution, comparable to the mechanisms of biological evolution depicted above. Mutations, both in nucleotides as well as whole chromosomes, are observed to occur over time, accumulate, and originate populations of genetically diverse cells. These cells compete in a certain environment and develop different characteristics due to changing selective pressure. Therefore, resistant cells, harbored by the tumor population, are able to survive the treatment and expand. In other words, a tumor has the capability of continuous adaptation (Willyard 2016). The mutations arising in evolving clones can either be selectively advantageous (so-called driver mutations), neutral (passenger mutations), or deleterious mutations (Beerenwinkel et al. 2015). 
Since the process of somatic evolution equals the process of biological evolution and speciation, one can draw a phylogenetic tree for cancer cells, with a common trunk,

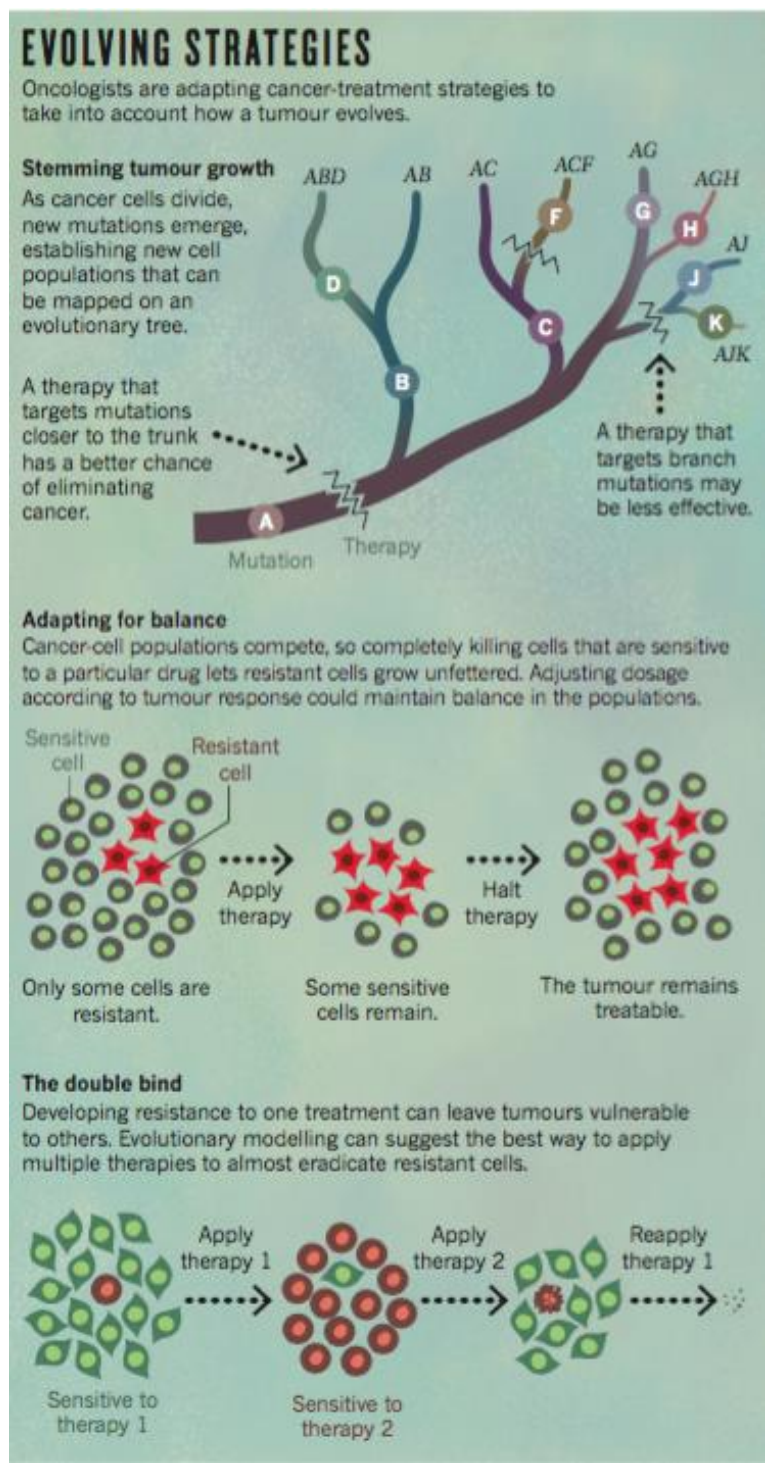

Figure 5 Evolving Strategies, Cancer: An Evolving Threat, Willyard, 2016 representing clones derived from a common ancestor cell, and various branches standing for sublines with later acquired mutations (Fig. 5) (Willyard 2016). In 1976, Peter C. Nowell was one of the first to support the hypothesis of stepwise mutations and clonal expansion as fundamental mechanisms in the initiation and progression of cancer. $\mathrm{He}$ suggested acquired genetic instability of tumor cells as an essential prerequisite for the occurrence of sublines of neoplastic cells and their stepwise selection. Chromosome studies in the 1950s underlined the idea of tumor "stem lines". According to this hypothesis, populations of cancer cells derive from a common progenitor cell, one single clone, and progress through a sequential selection of mutant sublines. He supported his theory by the fact that the same abnormal karyotype marker chromosomes had been found in all cells

of a primary tumor in earlier studies. At the same time, he recognized that tumors were mainly heterogeneous, which emphasized the idea of the appearance of subpopulations over time. In concrete terms, tumorigenesis was considered to start with the induction of genetic change in a single previously natural cell, which made it neoplastic concerning a selective growth advantage over the neighboring normal cells. A selective growth advantage could occur by metabolic advantages, avoidance of destruction by the immune system or by escape from the normal growth control. After a possible, sometimes extended, time of latency (resting state, G0) or limited growth, a tumor could turn to an active proliferative state (G1) again, and the 
evolutionary process of the sequential selection of increasingly abnormal sublines could follow.

It was further observed that the grade of malignancy correlated with increasing aneuploidy of the karyotype. Malignancy in this context was morphologically defined as an aberrant metabolic behavior, loss of hormonal dependence, increased growth rates, specific antigenic properties, the capacity of "continued variation" as well as invasion and metastasis. Furthermore, it was observed that cancer cells progressively lost their organelles and metabolic abilities for specific activities of a differentiated cell. These biological changes were found to be already present by the time macroscopic tumors appear in highly malignant cancers. Additionally, cancer cell populations exhibited a high degree of genetic instability regarding higher division rates and higher frequencies of mitotic errors or genetic alterations. Nowell concluded that neoplastic populations primarily depended on both mutation frequency and environmental pressures or positive selection processes. This observation led him to the assertion that each tumor was an "individual disease", formed by cells with multiple and non-deterministic alterations as a result of certain environmental pressures, such as the response of the immune system or therapeutic interventions (Nowell 1976). Subsequently, a myriad of scientists further developed the hypothesis of cancer evolution, of which only a few shall be mentioned here. Greaves stated that, even though chance influenced the frequency of passenger mutations, it frequently corresponded to the occurrence of particular driver mutations, which led to the conclusion that some mutations could have an impact on the probability of further mutational alterations and microenvironmental changes (Greaves \& Maley 2012). Nowak enclosed the importance of the spatial organization and the differentiation hierarchy in a cancer cell population concerning the resulting population structure to the previously known microenvironmental impact (Nowak et al. 2003). In 2013, Vogelstein provided critical insight into the molecular biology of evolutionary processes in carcinogenesis. He divided genes altered in a high percentage of cancers as "mountains" or "driver genes" and genes infrequently altered, so-called "hills" or "passenger genes". Whereas the "mountains" are usually very few, a large number of "hills" has been observed. So, according to Vogelstein, about 140 different driver genes have been identified, which have the capability to promote carcinogenesis. Each tumor presents between two and eight driver gene mutations. The remaining mutations occurring in a common tumor are passenger 
mutations, which account for more than $99.9 \%$ of all tumorous mutations. So the number of driver genes needed to initiate and promote tumor growth is very low. Indeed, their effect on the cell mechanisms could be reduced to 12 signaling pathways, which regulate three essential processes, "cell survival", "cell fate" and "genome maintenance" (Vogelstein et al. 2013). The mechanisms themselves, their impact on tumor initiation and progression, as well as a comparison to different classifications of cellular pathways, will be depicted below, in the paragraph "The Hallmarks of Cancer" (Vogelstein et al. 2013; Hanahan \& Weinberg 2000; Hanahan \& Weinberg 2011). Vogelstein described the concrete transformation of a benign cell to a malignant tumor by the acquisition of a series of mutations over time. The first acquired selective growth advantage is provided by the mutation of a gate-keeping gene, i.e. the APC gene so that a microscopic clone evolves. A second mutation, i.e. in KRAS, permits the clonal expansion of the population and thereby increased tumor growth. The following mutation might enable invasion and metastasis of a clonal subline. Thereby, linear regression has shown that more than half of all somatic mutations appear during the pre-neoplastic phase and that all of the mutations found in metastases have already been present in the majority of cells in the primary lesion. The fact that therapeutic response occurs in all metastatic lesions also supports this phenomenon. Vogelstein further questions the necessity and existence of so-called "metastasis genes" to enable invasion and metastasis and explains the metastatic process stochastically. According to him, the process of metastasis is rather random and non-deterministic, since only a small fraction of the vast amount of cells released by malignant tumors every day can establish metastatic lesions and the localizations of appropriate microenvironments are mostly random and infrequent. Moreover, he argues that it has even been shown that normal cells can grow into organoids when placed in certain environments.

The whole process of tumor growth and progression can take a long time until a highly malignant tumor has developed. Each driver mutation, according to Vogelstein, only provides a selective growth advantage of about $0.4 \%$ increase between birth and death of a cell. However, this growth advantage is potentiated over time so that a highly malignant tumor can evolve, even though it might need decades to develop. Besides, Vogelstein could show that the number of mutations in certain tumors of self-renewing structures directly correlates with age. Furthermore, increased presence of somatic mutations (mostly DNMT3A, TET2, and ASXL1) in the 
DNA of peripheral blood cells of phenotypically healthy people, mainly correlated with age, was found to be associated with an increased risk of hematologic cancer and all-cause-mortality (Jaiswal et al. 2014). Furthermore, common phenomena of tumorigenesis and biological evolution are the controversy over gradualism and punctuated equilibrium, the phenotypic plasticity, and the cellular heterogeneity. The question, if tumor growth is a gradual process, an accumulation of genetic mutations and clonal expansions, or a matter of punctuated equilibrium, a result of complex rearrangements or single catastrophes, is still unsolved, similar to the biological evolutionary process (Beerenwinkel et al. 2015; Vogelstein \& Kinzler 2015).

Vogelstein describes phenotypic plasticity as given by epigenetics, i.e. DNA methylation, which can alter under the influence of different microenvironments (Vogelstein et al. 2013). A different approach to explaining phenotypic plasticity is the assertion of so-called "Cancer Stem Cells", which are assumed to build up to $25 \%$ of all cancer cells in certain tumors (Gupta et al. 2009). They have been named according to their ability to initiate tumors in animals, to self-renew and to develop more differentiated progeny (Gupta et al. 2009). Even though their existence is frequently doubted and therefore still under discussion (Gupta et al. 2009), various findings contribute to the concept of cancer stem cells (Jordan, Craig T. et al. 2006; Gupta et al. 2009). Thereby their origin remains unknown. They are assumed to arise from normal tissue stem cells by mutation or from already mutated progenitor cells, which regain the ability of self-renewal (Jordan, Craig T. et al. 2006). Furthermore, the reversibility of the rise of cancer stem cells is unclear, especially in light of the possible reversibility of the epithelial-to-mesenchymal transition (EMT), which is assumed to be closely related to the existence of cancer stem cells and will be explained in detail below (Gupta et al. 2009).

In contrast to phenotypic plasticity, cellular heterogeneity, according to Vogelstein, is rather correlated with genetics. He distinguishes between intratumoral, inter- and intrametastatic and interpatient heterogeneity.

Intratumoral heterogeneity equals the biological process of speciation by random mutation in each cell division. Thereby the vast majority of all somatic mutations appear in all tumor cells, which then form the "trunk" of the phylogenetic tree, and only a small part is built by "branch"-mutations, which present the starting points for intermetastatic heterogeneity. This intermetastatic heterogeneity is of less 
importance, because, despite the fact that each metastatic lesion evolves about 20 clonal mutations not shared by other metastatic lesions, these mutations are mainly passenger mutations and therefore without any observed impact on tumor progression or therapeutic response. In contrast, intrametastatic heterogeneity describes new mutations in one metastatic lesion and is of greater relevance concerning the probability of drug resistance. If already existent before the onset of targeted therapy, they build the seeds for subsequent recurrence.

Furthermore, Vogelstein observed that even among the same tumor types in different patients, only a small amount of alterations occurs in the same genes. This variation can be explained by factors determined by germline variants or related to nongenetic phenomena (Vogelstein et al. 2013).

As a consequence, many authors have proposed a fundamental rethinking of cancer therapy. For example, Nowell suggested the creation of a tumor environment, which would force the malignant cell population to limit growth by switching into a state of moderate division rate and controlled differentiation or "target an antigen-like structure of all clones". Thereby, he aimed to exploit the fact, that tumor growth follows the rules observed in biological evolution (Nowell 1976). Others share the opinion that targeted therapy should include multiple agents applied either at the same time to avoid the positive selection of a mutated clone right from the onset of treatment (Vogelstein et al. 2013), or in altering dosages as an "adaptive therapy". Thereby, the therapy is strictly adjusted correlating to the observed progression of tumor heterogeneity to keep the tumor in a steady state. It has further been depicted that although a tumor might have become resistant to a certain targeted therapy, desensitization can be observed after the application of a second drug, termed "evolutionary double bind". Thereby, the alternating application of two different drugs could be reasonable to lower the selective pressure and subsequent positive selection of resistant subclones (Willyard 2016).

\subsubsection{Entropy}

\subsection{History and principles of entropy}

The role of entropy in biological evolution has been discussed for decades. Undoubtedly, entropy exists in chemical as well as in biological processes and changes with evolutionary development. However, both the impact of entropy on 
evolutionary processes, especially on values such as information, predictability, and disorder, as well as the exact definition of entropy on biological evolution are still controversial (Blokh \& Stambler 2016; Brooks \& Wiley 1986; Collier 1986). This uncertainty can to a large extent be attributed to the fact, that the term "entropy" is used in two standard concepts in both thermodynamics and information theory. Whereas the concepts seem to resemble each other, the term is applied in two distinct ways and should not be confounded.

In thermodynamics, entropy stands for the thermal energy of a system per unit temperature, which is not available for valuable work anymore. The term was coined by physicist Rudolf Clausius in 1850 to test the possible violation of the second law of thermodynamics (Drake 2016a). It postulates that a "cyclic transformation whose only final result is to transform heat extracted from a source which is at the same temperature throughout into work is impossible" (Drake 2016b). Further, it claims that a "cyclic transformation whose only final result is to transfer heat from a body at a given temperature to a body at a higher temperature is impossible" (Drake 2016b). Depicted mathematically, the increase of the entropy $S$ of a system, if an amount of heat $Q$ flows into a thermal reservoir with a constant temperature $T$, can be defined as

$$
\Delta S=\frac{Q}{T}
$$

(Drake 2016b).

For a heat $\mathrm{Q}$, which flows from reservoir $\mathrm{R} 1$ to reservoir $\mathrm{R} 2$ at temperatures $\mathrm{T} 1$ and T2, the change of entropy is

$$
\Delta S=\frac{Q}{T 2}-\frac{Q}{T 1}
$$

(Drake 2016b).

For a spontaneous flow of heat, which in nature is irreversible and only possible from a reservoir at a higher temperature to a reservoir at a lower temperature, it follows that $\Delta S$ is positive if $T 1>T 2$ (Drake 2016b).

Concerning biological processes, the concept depicted above bears the limitations, that organisms cannot be considered closed chemical systems since energy supply is nearly limitless and permanent exchange of substances and energy between the organism and its environment is given (Collier 1986). As a consequence, a more 
"soft" definition of entropy concerning thermodynamic processes has been proposed. As valuable work is assumed to be achieved by ordered molecular motion, entropy is sometimes described as a measure of the molecular disorder of a system (Drake 2016a). This rather inaccurate definition of the thermodynamic term "entropy" gets closer to the "entropy" used in information theory.

In information theory, "entropy [serves as a] measure of uncertainty of a random variable" (Blokh \& Stambler 2016). The entropy $\mathrm{H}$ of a random variable $\mathrm{X}$ is zero if the number of probable outcomes $n=1$. In other words, if there is only one probable outcome, the event is certain, and the entropy measures zero.

By implication, random variables with equally likely outcomes (probability equals $1 / n$ ) have the highest entropy. So, in this case, the uncertainty depends on the number of equally probable outcomes $n$ (Blokh \& Stambler 2016).

If the number of outcomes of two variables is equal, the variable with equally probable outcomes has a higher entropy than the variable with unequally probable outcomes (Blokh \& Stambler 2016). An adequate tool to measure the uncertainty for a discrete variable $X$ is the normalized Shannon entropy (Blokh \& Stambler 2016). Its maximal value is independent of the number of outcomes $n$ and therefore more suitable for biological processes, as the number of possible outcomes normally is an unknown variable to be tested. Furthermore, it is a dimensionless measure and thereby allows comparison of different model systems.

\subsection{Cancer as an entropic disease}

As described above, evolution is the result of random genetic and epigenetic alterations and the subsequent natural selection. Genetic and epigenetic change can alternatively be characterized as a change of information content of an organism or species. Brooks and Wiley proposed that evolutionary processes go along with entropy changes, an increase of entropy, respectively. In their concept they focused on evolution as a change of information resulting from "increases in species organization and decreases in species cohesiveness" (Collier 1986). According to them, both developments are related to an increase of entropy in the affected information system, since both correlate to great information alterations and thereby a decrease of certainty and predictability (Collier 1986). As they were criticized for mingling the two different concepts of entropy in their argumentation, both concepts will be explored separately in the following. 
Being aware of the limitation of the thermodynamic theorem concerning the application in biological processes, the "soft" assertion of entropy as a measure of molecular disorder is preferred below. If we assume that energy is needed to build and keep molecular order, the entropy of a system rises with the loss of energy and, consequently, the loss of order and vice versa. Thus, ongoing evolution, which produces new species of higher molecular order, correlates with higher levels of energy absorbed in the system and a decrease in entropy.

As a consequence, against the background of the frequent observation, that cancerous lesions show a loss of cohesion and order (Hanahan \& Weinberg 2011), one can conclude, that the evolution of cancer correlates with an increase of entropy in terms of thermodynamics.

In information theory, in contrast, biological evolutionary processes are assumed to bring along alterations in the information content of a system and thereby increase the variability or uncertainty of outcome with the rising order of species. In other words, biological evolution correlates with an increase of entropy (Blokh \& Stambler 2016). Accordingly, cancer is defined by a loss of variability and mobility and an increase of rigidity. Both Blokh and Wiley and Brooks conclude that cancer must therefore correlate with a decrease of entropy in terms of information theory (Blokh \& Stambler 2016; Brooks \& Wiley 1986; Collier 1986).

This brief depiction of the role of entropy in biological and cancerous evolution in the two different concepts of entropy reveals the contrast between the two concepts and the related impossibility of a general statement about the increase or decrease of entropy in the evolution of cancer. But, nevertheless, both concepts indicate, that the development of cancer is not the result of continued biological evolution, but rather a contrary process. Since the applicability of the principles of evolution are frequently observed in carcinogenesis and therefore not affected by this observation, we propose to strictly use the term somatic evolution in carcinogenesis to emphasize the difference between biological evolution, including speciation, and cancerous evolution.

\subsubsection{Probability and Chance}

Probability and Chance play crucial roles both in biological evolution and in carcinogenesis. Whereas probability is a rather mathematical term to make indeterminist phenomena describable and measurable, Chance is a rather 
philosophical aspect and was already assumed to be "an unaccountable force which to some extent thwarts natural law" by Epicurus and Lucretius in the $4^{\text {th }}$ century BC (Long 1977). They proposed that sometimes the direct paths of atoms in the universe warp and the atoms "swerve" (Luzzatto \& Pandolfi 2015). Even though the physical explanation remains controversial, their intention to define the force of spontaneity, indeterminacy and eventuality in natural processes was not too far off and contrasted the concept of necessity and determinism (Long 1977).

Recently, Tomasetti and Vogelstein reported a high correlation between the lifetime risk of certain tumor types in certain tissues and the estimated total number of stem cell divisions in the related organ tissue (Fig. 6). Thus, they elucidated the role of chance in carcinogenesis and provided evidence that somatic mutations and their accumulation are to a vast extent stochastic phenomena (Tomasetti \& Vogelstein 2015).

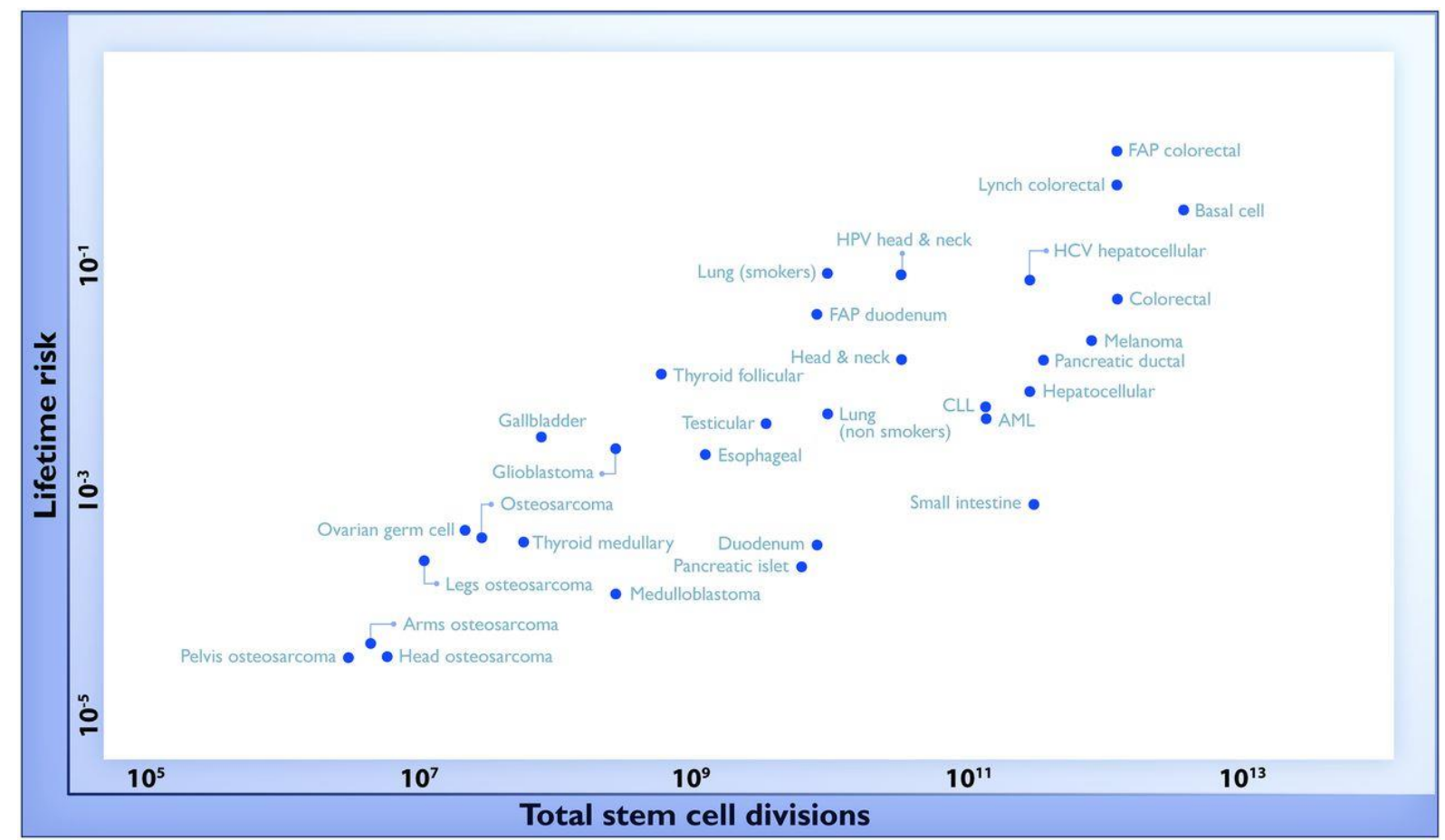

$\mathrm{FAP}=$ Familial Adenomatous Polyposis $\diamond \mathrm{HCV}=$ Hepatitis $\mathrm{C}$ virus $\diamond \mathrm{HPV}=$ Human papillomavirus $\diamond \mathrm{CLL}=$ Chronic lymphocytic leukemia $\diamond \mathrm{AML}=\mathrm{Acute}$ myeloid leukemia

Figure 6 Relationship between the number of stem cell divisions and the lifetime risk of cancer in the related tissue, Variation in cancer risk among tissues can be explained by the number of stem cell divisions, Tomasetti \& Vogelstein, 2015

Assuming that each DNA replication bore the risk of random genomic alterations and that the endogenous mutation rate of all human cell types was almost identical, they concluded that there had to be a quantitative correlation between the lifetime number 
of cell divisions and the lifetime risk of cancer in the related organs. What they found was a strong correlation of 0,81 (Spearman's rho) and 0.804 (Pearson's linear correlation), which extended across five orders of magnitude. By implication, this correlation predicts that $65 \%$ of the differences in cancer risk throughout different organs and tissues can be explained by the local number of stem cell divisions and only one-third of cancer risk variation occurs due to hereditary or environmental effects. To discriminate the observed stochastic effects from further possible causes, they introduced an "extra risk score" (ERS) and correspondingly, classified the investigated tumors (Fig. 7). They found tumors within the group of high-ERS to belong to the tumors with a substantial evidence about environmental or hereditary causative factors, which further stressed the impact of the stochastic effects arising in stem cell divisions (Tomasetti \& Vogelstein 2015).

\section{Clustering of cancer types}

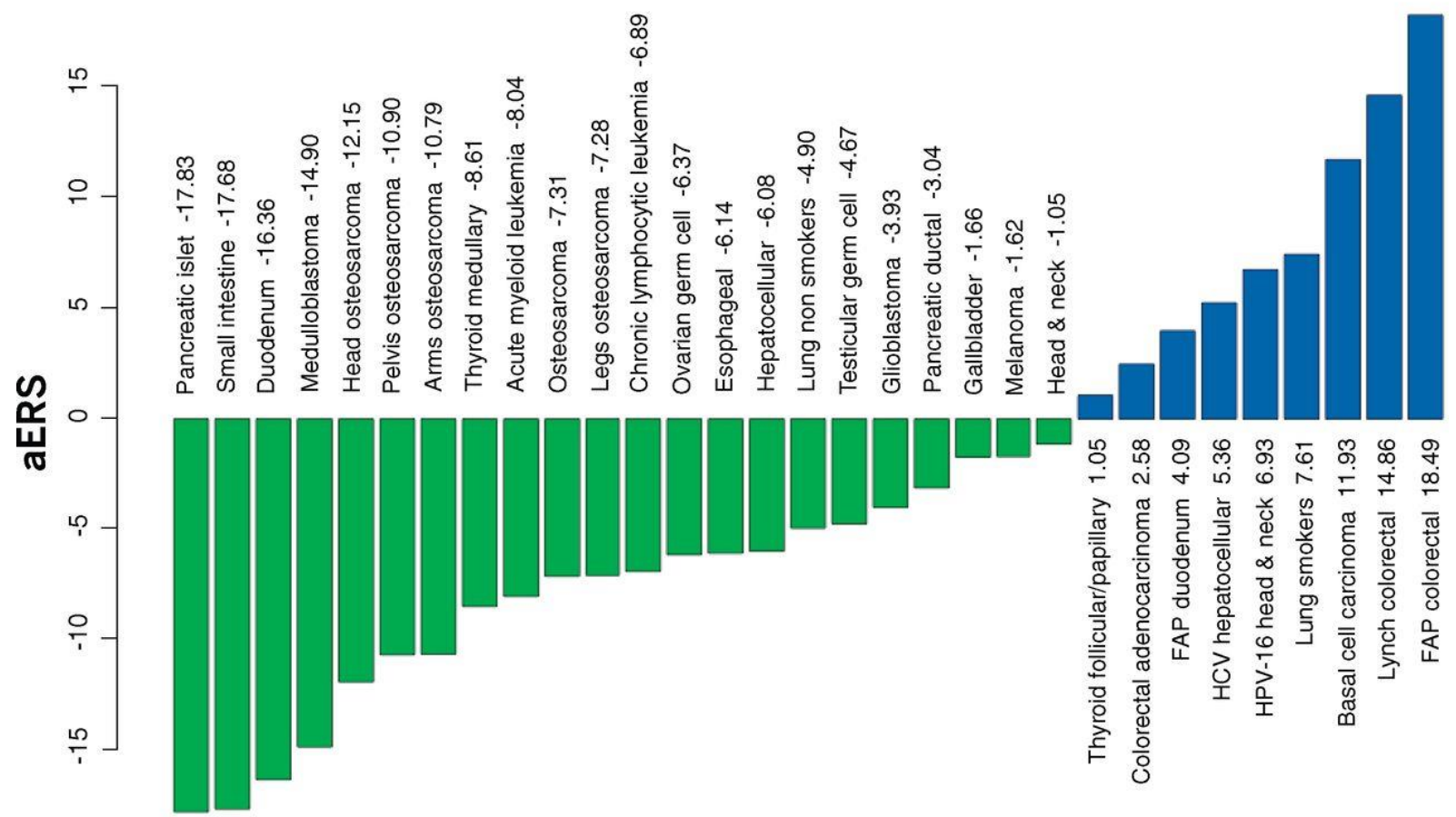

Figure 3 Stochastic (replicative) factors versus environmental and inherited factors: $R$-tumor versus $D$-tumor classification, Variation in cancer risk among tissues can be explained by the number of stem cell divisions, Tomasetti \& Vogelstein, 2015

Referring to this observation, Luzzatto and Pandolfi later offered a mathematical approach to illustrate the interplay of heredity, environment, and chance. According to them, somatic mutations are naturally random, stochastic events, which occur by pure chance with a probability of $10^{\wedge}-7$ per gene per cell division. Additionally, they 
offer an attempt to explain this stochastic phenomenon by mispairing in DNA replication resulting from an equilibrium between tautomeric forms of purine and pyrimidine bases apparent in solution.

They deduce, that the number of accumulated somatic mutations $M$, which approximately equals the cancer risk, is proportional to the number of cell divisions $D$ with the proportionality factor $\mu$ as the mutation rate (Fig. 8):

$M=\mu \mathrm{M}=\mu \times \mathrm{D}$ (Luzzatto \& Pandolfi 2015).

They admit that $D$ may vary the most from one tissue to another and may thereby most determining aspect of frequency variations. However, they also point out, that both $\mathrm{m}$ that both $\mu$ that both $\mu$ and $\mathrm{D}$ can be influenced by hereditary as well as environmental factors and are not fixed as variables (Luzzatto \& Pandolfi 2015), a fact, which is only slightly addressed by Tomassetti and Vogelstein (Tomasetti \& Vogelstein 2015).

They do not doubt the impact of chance on the evolution of cancer. However, they highlight the fact, that chance might be the predominant factor if cancer develops in a patient with a low $\mu$ and a low $D$, but will, in contrast, have an decreased effect on the tumour development, if the "ERS" is high (Luzzatto \& Pandolfi 2015).

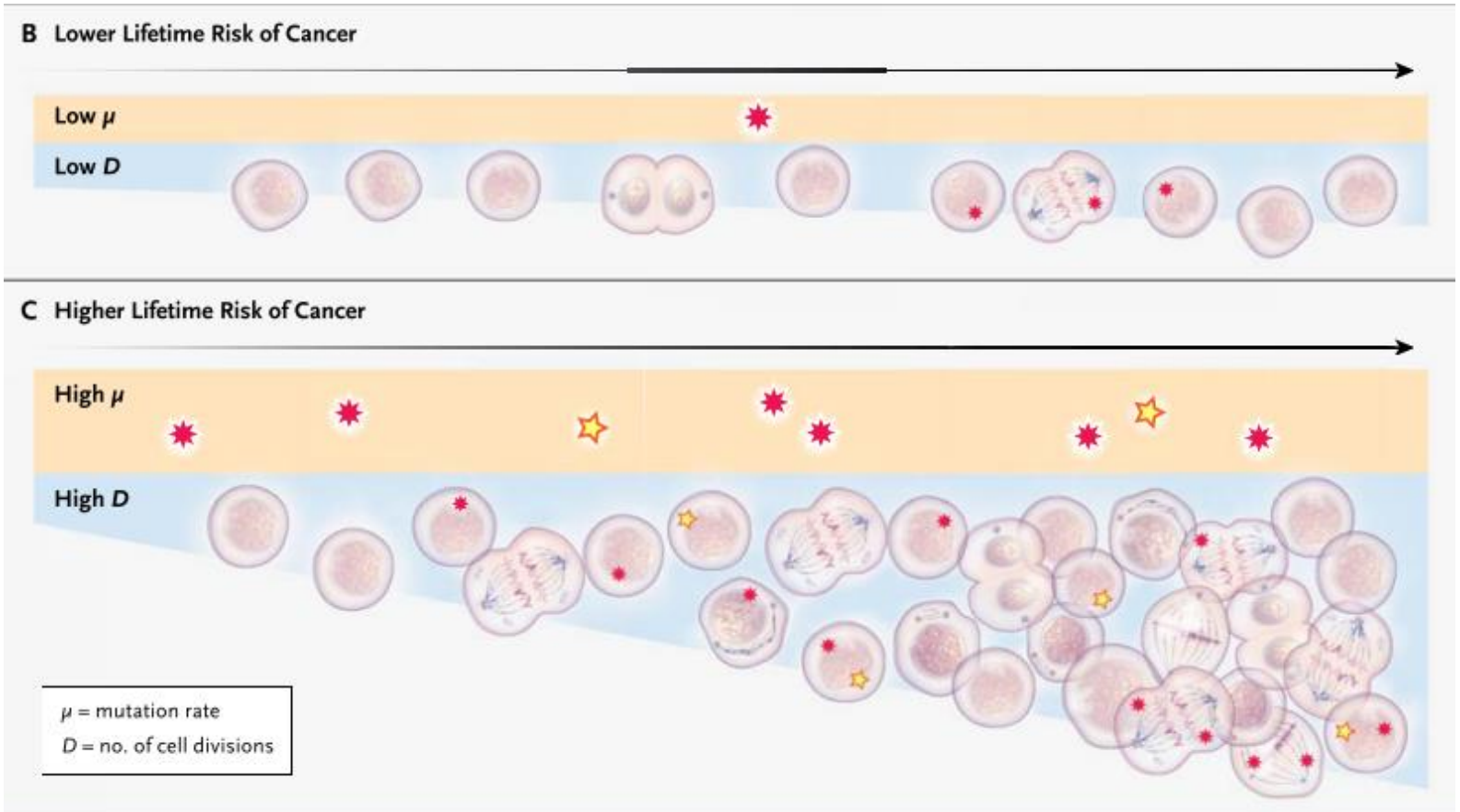




\subsubsection{Recent Research Strategies}

The latest insights into the genesis of cancer, especially the wide and rapidly increasing knowledge of the genome of the malignant cell and the processes on a molecular level, have led to innovative approaches in Cancer Research. While research on cancer stem cells and clonal evolution is being enhanced, novel initiatives aim at cancer vaccines, early cancer recognition, single cell genomic analysis and immunotherapy. A wide range of scientists focuses on the deciphering and registration of a vast amount of cancer genomes of all cancer types (Hayes \& Kim 2015), while superordinate ambitions are to improve the system of data sharing to establish a research fund for excellent and rather unconventional ideas and use of novel scientific methods. Inevitably, the claim for multidisciplinary approaches, considering bioinformaticians, "data scientists" (McAfee \& Brynjolfsson 2012) "genomic navigators" (Hayes \& Kim 2015), as well as basic researchers and clinicians (Vaidyanathan 2012), grows. All of this is meant to broaden the horizon of scientists and researchers to exploit the full potentialities of the $21^{\text {st }}$ century, the information age (Lowy \& Collins 2016). Against the background of the shift of clinical trials to next-generation genetics, the question comes up, if the ever since appreciated Evidence-Based-Medicine (EBM) is still the best scientific approach to obtain the best treatment for a patient. One should rather take into account, if there should be a shift in statistical awareness as well, through a change of focus towards a Personalized Medicine (PM) (de Leon 2012). Especially in oncology, PM is considered as the future trial strategy, for genomic information can be utilized for diagnosis, prognosis and the prediction of drug resistance (Hayes \& Kim 2015). In contrast to the principles of randomized-controlled-trials, which are dependent on the assumption that patients are a homogenous population with the same prerequisites, risks, and therapeutic responses and require a high number of subjects to achieve a statistically relevant result, personalized medicine allows the investigation of small numbers of patients by rather precise characterization which leads to predictions and postulations for individual patients (Vaidyanathan 2012). As the uncontrolled individualization of therapies can entail serious harms because of a lack of regulation, the International Society of Clinical Research (ISSCR) has recently 
proposed a clinical translation employing "responsible innovation". Concerning their assumption of innovation, this pathway should only be eligible under very special circumstances, like small groups of critically ill patients. According to Sugarman, to expand the applicability of the so-called "Innovation Pathway", it is necessary to improve the system of data sharing including failures and negative data outcomes to guarantee a continuously safe clinical translation (Sugarman 2012).

\subsubsection{The Cancer Hallmarks - A Synthesis}

Table 3 gives an overview of the classified and, thus, synthesized hallmark capabilities described by Hanahan and Weinberg (Hanahan \& Weinberg 2011), Vogelstein (Vogelstein et al. 2013) and Torrente et al. (Torrente et al. 2016).

\begin{tabular}{|c|c|c|c|}
\hline Hanahan \& Weinberg 2011 & $\begin{array}{l}\text { Vogelstein et al. } \\
\qquad 2013\end{array}$ & Torrente et al. 2016 & Groten et al. 2016 \\
\hline Hallmarks of Cancer & $\begin{array}{l}\text { Core Cellular } \\
\text { Processes }\end{array}$ & $\begin{array}{c}\text { Genes overexpressed in } \\
\text { cancer }\end{array}$ & Suggested Hallmarks \\
\hline $\begin{array}{l}\text { Evading Growth } \\
\text { Suppressors }\end{array}$ & Cell survival & EMR2 & $\begin{array}{c}\text { Growth/Apoptosis } \\
\text { Balance }\end{array}$ \\
\hline \multirow[t]{3}{*}{$\begin{array}{l}\text { Sustaining Proliferative } \\
\text { Signaling }\end{array}$} & & PTP4A3 $(* *)$ & \\
\hline & & RPS6KB1 & \\
\hline & & RGS1 & \\
\hline \multirow[t]{2}{*}{$\begin{array}{l}\text { Tumor-Promoting } \\
\text { Inflammation }\end{array}$} & & TREM2 & \\
\hline & & MAP3K12 & \\
\hline \multirow[t]{2}{*}{$\begin{array}{l}\text { Evading Immune } \\
\text { Destruction }\end{array}$} & & TDO2 & \\
\hline & & ANXA11 & \\
\hline $\begin{array}{l}\text { Enabling Replicative } \\
\text { Immortality }\end{array}$ & $\begin{array}{c}\text { Genome } \\
\text { maintenance }\end{array}$ & $?$ & $\begin{array}{c}\text { Genomic } \\
\text { Fidelity/Immortality }\end{array}$ \\
\hline \multirow[t]{4}{*}{$\begin{array}{l}\text { Genome Instability and } \\
\text { Mutation }\end{array}$} & & DDX11 & \\
\hline & & BLM & \\
\hline & & NUDT1 & \\
\hline & & NUDT1 & \\
\hline Activating Invasion and & Cell Fate & PTP4A3 $\left({ }^{* *}\right)$ & Stem Cell Features \\
\hline
\end{tabular}




\begin{tabular}{|l|c|}
\hline Metastasis & MMP9 \\
\hline & LEF1 \\
\hline Resisting Cell Death & none \\
\hline Inducing Angiogenesis & \\
\hline Reprogramming Energy & \\
\hline Metabolism & \\
\hline
\end{tabular}

Table 3 The Hallmarks of Cancer, A Synthesis, Hanahan \& Weinberg, 2011, Vogelstein et al., 2013, Torrente et al., 2016, Groten et al., 2016 (in press)

It becomes evident that all proposed concepts of the most fundamental traits of cancer cells correspond to each other. One can assign both the "Hallmarks of Cancer", described by Hanahan and Weinberg and the genes found to be overexpressed in cancer cells by Torrente et al. to one of the three "Core Cellular Processes" suggested by Vogelstein et al.

Probably crucial cancer cell features, which can be considered to be missing in this concept are both the block of differentiation and the retrieval of phenotypic plasticity (Kutschera \& Niklas 2004; Vogelstein et al. 2013). The differentiation block was already proposed by Hansemann around 1900 (Hajdu 2012b) and phenotypic plasticity is mainly assumed to be achieved by the reacquisition of stem cell properties by cancer cells (Kreso \& Dick 2014).

\section{Summary}

Cancer is still the second-leading cause of death worldwide. Recently, novel concepts and rethinking of previously published concepts are changing the oncologic research landscape (Lowy \& Collins 2016). To address the rising need for innovative research approaches (Lowy \& Collins 2016) the overall aim of this investigation was to investigate the essential phenotypic "hallmarks" of a cancer cell. The term "Hallmarks of Cancer" has thereby been adopted from Hanahan and Weinberg (Hanahan \& Weinberg 2000; Hanahan \& Weinberg 2011) and defines the most 
fundamental phenotypic characteristics of cancer cells, which are assumed to distinguish the latter from normal cells. Aiming to achieve our concept of phenotypic cancer hallmarks, we critically considered the pertinent literature about the hallmarks selected by Hanahan and Weinberg, the genetic hallmarks, focusing on gene expression, the principles of biological and somatic evolution, entropy and chance in cancer, recent research strategies, as well as the history of cancer research. As a result, the identified hallmark characteristics were evaluated and, finally, synthesized. Based on this synthesis, mathematical algorithms were developed to describe the hallmark pathways of carcinogenesis.

Subsequently, a computational simulation of carcinogenesis has been drawn up employing these mathematical algorithms, which will be described in detail in a subsequent publication (Groten et al., 2016, in press).

\section{References}

Alli I (2013) 101 Selected Sayings Mahatma Gandhi, 
Almendro V, Marusyk A \& Polyak K (2013) Cellular Heterogeneity and Molecular

Evolution in Cancer. Annu. Rev. Pathol. Mech. Dis 8, 277-302.

American Cancer Society (2014) The History of Cancer. Cancer.

Anon (2016) wikiquotes. Available at: https://en.wikiquote.org/wiki/Albert_Einstein.

Arksey H \& O'Malley L (2005) Scoping studies: towards a methodological framework. Int. J. Soc. Res. Methodol. 8, 19-32.

Beerenwinkel N, Schwarz RF, Gerstung M \& Markowetz F (2015) Cancer evolution: mathematical models and computational inference. Syst. Biol. 64, e1-25.

Berger DP, Engelhardt R \& Mertelsmann R (2014) Das Rote Buch - Hämatologie und Internistische Onkologie,

Blokh D \& Stambler I (2016) The application of information theory for the research of aging and aging-related diseases. Prog. Neurobiol.

Boveri T (1914) Zur Frage der Entstehung maligner Tumoren.

Brooks DR \& Wiley EO (1986) Evolution as Entropy. Pubmedcentralnihgov.

Bundesamt S (2014) Todesursachen in Deutschland. Stat. Bundesamt 12.

Cairns J (1975) Mutation selection and the natural history of cancer. Nature 255, cp1-

De Carvalho DD, Sharma S, You JS, Su S-F, Taberlay PC, Kelly TK, Yang X, Liang G \& Jones PA (2012) DNA Methylation Screening Identifies Driver Epigenetic Events of Cancer Cell Survival. Cancer Cell 21, 655-667.

Coley WB (1893) The treatment of malignant tumors by repeated inoculations of erysipelas: with a report of ten original cases. Americna J. Med. Sci. 105, 487510.

Collier J (1986) Entropy in evolution. Biol. Philos. 1, 5-24.

Czarnetzki A (1980) Pathological changes in the morphology of the young paleolithic skeletal remains from Stetten (south-west Germany). J. Hum. Evol. 9, 15-17.

David a R \& Zimmerman MR (2010) Cancer: an old disease, a new disease or something in between? Nat. Rev. Cancer 10, 728-733.

Deutsches Krebsforschungszentrum (2016) Zahlen und Fakten - Deutsches Krebsforschungszentrum. Available at: https://www.dkfz.de/de/dkfz/quickfacts.html [Accessed October 4, 2016].

DeVita VT \& Rosenberg SA (2012) Two Hundred Years of Cancer Research. $N$. Engl. J. Med. 366, 2207-2214.

Drake GWF (2016a) Entropy. Britannica. Available at: https://www.britannica.com/science/entropy-physics.

Drake GWF (2016b) Thermodynamics - Isothermal and adiabatic processes | Britannica.com. Encycl. Br. Available at:

https://www.britannica.com/science/thermodynamics/Isothermal-and-adiabaticprocesses\#toc258544 [Accessed August 13, 2016].

Druker BJ, Guilhot F, O'Brien SG, Gathmann I, Kantarjian H, Gattermann N, Deininger MWN, Silver RT, Goldman JM, Stone RM, Cervantes F, Hochhaus A, Powell BL, Gabrilove JL, Rousselot P, Reiffers J, Cornelissen JJ, Hughes T, Agis H, Fischer T, Verhoef G, Shepherd J, Saglio G, Gratwohl A, Nielsen JL, Radich JP, Simonsson B, Taylor K, Baccarani M, So C, Letvak L \& Larson RA (2006) Five-Year Follow-up of Patients Receiving Imatinib for Chronic Myeloid Leukemia. N. Engl. J. Med. 355, 2408-2417.

Gabrilove, Janice L MD, Jakubowski, Ann, M.D. PD, Scher, Howard MD \& Sternberg, Cora MD (1988) Effect of Granulocyte Colony-Stimulating Facotr on Neutropenia and Associated Morbidity due to Chemotherapy for Transitional-Cell Carcinoma of the Urothelium. 318, 1414-22. 
Grant MJ \& Booth A (2009) A typology of reviews: an analysis of 14 review types and associated methodologies. Heal. Inf. Libr. J. 26, 91-108.

Greaves M \& Maley CC (2012) Clonal evolution in cancer. Nature 481, 306-313.

Groten J, Georg M, Worm O, Borner C, Mertelsmann R (in press) Towards

Simulating Carcinogenesis: Modeling and Simulating Carcinogenesis,

Hematopoietic Tissue Homeostasis and Leukemogenesis

Gupta PB, Chaffer CL \& Weinberg RA (2009) Cancer stem cells: mirage or reality?

Hajdu SI (2011a) A note from history: Landmarks in history of cancer, part 1. Cancer

117, 1097-1102.

Hajdu SI (2011b) A note from history: Landmarks in history of cancer, part 2. Cancer $117,2811-2820$.

Hajdu SI (2012a) A note from history: Landmarks in history of cancer, part 3. Cancer $118,1155-1168$.

Hajdu SI (2012b) A note from history: Landmarks in history of cancer, part 4. Cancer 118, 4914-4928.

Hajdu SI (2004) Greco-Roman thought about cancer. Cancer 100, 2048-2051.

Hajdu SI \& Darvishian F (2013) A note from history: Landmarks in history of cancer, part 5. Cancer 119, 1450-1466.

Hajdu SI \& Vadmal M (2013) A note from history: Landmarks in history of cancer, part 6. Cancer 119, 4058-82.

Hajdu SI, Vadmal M \& Tang P (2015) A note from history: Landmarks in history of cancer, part 7. Cancer 121, 2480-2513.

Hanahan D \& Weinberg RA (2011) Hallmarks of Cancer: The Next Generation. Cell $144,646-674$.

Hanahan D \& Weinberg RA (2000) The Hallmarks of Cancer. Cell 100, 57-70.

Hayes DN \& Kim WY (2015) The next steps in next-gen sequencing of cancer genomes. J. Clin. Invest. 125, 462-468.

IARC (2016a) About IARC - IARC History. Available at:

https://www.iarc.fr/en/about/iarc-history.php [Accessed October 4, 2016].

IARC (2016b) Globocan 2012. Http://Www-Dep.larc.Fr/ GLOBOCAN, 2012-2013.

Jaiswal S, Fontanillas P, Flannick J, Manning A, Grauman P V, Mar BG, Lindsley

RC, Mermel CH, Burtt N, Chavez A, Higgins JM, Moltchanov V, Kuo FC, Kluk MJ, Henderson B, Kinnunen L, Koistinen HA, Ladenvall C, Getz G, Correa A, Banahan BF, Gabriel S, Kathiresan S, Stringham HM, McCarthy MI, Boehnke M, Tuomilehto J, Haiman C, Groop L, Atzmon G, Wilson JG, Neuberg D, Altshuler D \& Ebert BL (2014) Age-related clonal hematopoiesis associated with adverse outcomes. N. Engl. J. Med. 371, 2488-98.

Jordan, Craig T. PD, Guzman, Monica L. PD \& Noble, Mark PD (2006) Cancer Stem Cells. N. Engl. J. Med. 355, 1253-61.

Klein CA (2013) Selection and adaptation during metastatic cancer progression. Nature 501, 365-372.

Kreso A \& Dick JE (2014) Cell Stem Cell Evolution of the Cancer Stem Cell Model. Stem Cell 14, 275-291.

Kutschera U \& Niklas KJ (2004) The modern theory of biological evolution: an expanded synthesis. Naturwissenschaften 91, 255-276.

Lane DP (1992) Cancer. p53, guardian of the genome. Nature 358, 15-16.

de Leon J (2012) Evidence-based medicine versus personalized medicine: Are they enemies? J. Clin. Psychopharmacol. 32, 153-164.

Levac D, Colquhoun H \& O'Brien KK (2010) Scoping studies: advancing the methodology. Implement. Sci. 5, 69. 
Long AA (1977) Chance and natural law in Epicureanism. Phronesis 22, 63-88.

Lowy DR \& Collins FS (2016) Aiming High - Changing the Trajectory for Cancer. N. Engl. J. Med. 374, 1901-1904.

Luzzatto L \& Pandolfi PP (2015) Causality and Chance in the Development of Cancer. N. Engl. J. Med. 1, 84-88.

Marks R \& Mertelsmann R (2016) Tumor Immunology and Immunotherapy in Cancer Patients. Springer $B$. Press.

McAfee A \& Brynjolfsson E (2012) Big Data. The management revolution. Harvard Buiness Rev. 90, 61-68.

Merlo LMF, Pepper JW, Reid BJ \& Maley CC (2006) Cancer as an evolutionary and ecological process. Nature 6, 924-935.

Mertelsmann R \& Georg M (2016) Cancer : Modeling evolution and natural selection , the „Mitosis Game “.

Muntean AG \& Hess JL (2009) Epigenetic Dysregulation in Cancer. Am. J. Pathol. $175,1353-1361$.

National Cancer Institute (2016a) National Cancer Act of 1937. Natl. Cancer Inst. Available at: http://www.cancer.gov/about-nci/legislative/history/national-canceract-1937.

National Cancer Institute (2016b) National Cancer Act of 1971. Natl. Cancer Inst. Available at: http://www.cancer.gov/about-nci/legislative/history/national-canceract-1971.

Nowak MA, Michor F \& Iwasa Y (2003) The linear process of somatic evolution. Proc. Natl. Acad. Sci. 100, 14966-14969.

Nowell PC (1976) The clonal evolution of tumor cell populations. Science 194, 23-8.

Obama B (2016) Memorandum -- White House Cancer Moonshot Task Force.

Pelossof R, Singh I, Yang JL, Weirauch MT, Hughes TR \& Leslie CS (2015) Affinity regression predicts the recognition code of nucleic acid-binding proteins. Nat. Biotechnol. 33, 1242-1249.

Riedmiller M, Gabel T, Hafner R \& Lange S (2009) Reinforcement learning for robot soccer. Auton. Robots 27, 55-73.

Shchors K \& Evan G (2007) Tumor angiogenesis: Cause or consequence of cancer? Cancer Res. 67, 7059-7061.

Smith E \& Breasted JH (1930) The Edwin Smith Surgical Papyrus Published in Facsimile and Hieroglyphic Transliteration with Translation and Commentary in Two Volumes by James Henry Breasted. Univ. Chicago Press.

Sugarman J (2012) Questions Concerning the Clinical Translation of Cell-Based Interventions under an Innovation Pathway. J. Law, Med. Ethics 40, 945-950.

Suthaharan S (2016) Machine Learning Models and Algorithms for Big Data Classification, Boston, MA: Springer US.

Sütterlin T (2015) Entwurf und Realisierung eines computergestützten Systems zur in silico Modellierung und Simulation von Epithelgeweben.

Tomasetti C \& Vogelstein B (2015) Variation in cancer risk among tissues can be explained by the number of stem cell divisions. Science (80-. ). 347, 78-81.

Torrente A, Lukk M, Xue V, Parkinson H, Rung J \& Brazma A (2016) Identification of Cancer Related Genes Using a Comprehensive Map of Human Gene Expression. PLoS One 11, e0157484.

UICC (2014) Introduction to UICC.

Vaidyanathan $\mathrm{G}$ (2012) Redefining clinical trials: The age of personalized medicine. Cell 148, 1079-1080.

Virchow R (1859) Cellular Pathology as Based Upon Physiolocal and pathological 
history,

Vogelstein B \& Kinzler KW (2015) The Path to Cancer - Three Strikes and You're out. N. Engl. J. Med. 37320.

Vogelstein B, Papadopoulos N, Velculescu VE, Zhou S, Diaz LA, Kinzler KW, Wood LD, Parsons DW, Jones S, Govindan R, Gryfe R, Gallinger S, Palles C, Nowell

PC, Fearon ER, Vogelstein B, Kinzler KW, Vogelstein B, Jones S, Bozic I,

Tomasetti C, Vogelstein B, Parmigiani G, Laurenti E, Dick JE, Welch JS,

Yachida S, Kerbel RS, Bernards R, Weinberg RA, Yu M, Stott S, Toner M, Maheswaran S, Haber DA, Komori J, Boone L, DeWard A, Hoppo T, Lagasse E, Pelizzola M, Ecker JR, Parmigiani G, Meyerson M, Gabriel S, Getz G, Carter H, Youn A, Simon R, Kaminker JS, Zhang Y, Watanabe C, Zhang Z, Michaelson JJ, Nik-Zainal S, Thiagalingam S, Forbes SA, Yan H, Zhao S, Ward PS, Dang L, Pear WS, Aster JC, Nicolas M, Weng AP, Agrawal N, Stransky N, Agrawal N, Parsons DW, Pasqualucci L, Morin RD, Grasso CS, Ellis MJ, Wiegand KC, Jones S, Jones S, Wang K, Huang J, Imielinski M, Rudin CM, Delhommeau F, Schwartzentruber J, Wu G, Ley TJ, Dalgliesh GL, Suvà ML, Riggi N, Bernstein BE, Papaemmanuil E, Graubert TA, Yoshida K, Jiao Y, Cesare AJ, Reddel RR, Heaphy CM, Heiden MG Vander, Cantley LC, Thompson CB, Lu C, Turcan S, Stephens PJ, Bass AJ, Tomlins SA, Soda M, Armitage P, Doll R, Böttcher R, Forster M, Ding J, Beal MA, Glenn TC, Somers CM, Mertes F, Gundry M, Vijg J, Biankin A V., Yan H, Kinzler KW, Vogelstein B, Huang FW, Horn S, Xue W, Solimini NL, Beggs AD, Feinberg AP, Tycko B, Jones PA, Baylin SB, Höglund M, Gisselsson D, Säll T, Mitelman F, Shibata D, Schaeffer J, Li ZH, Capella G, Perucho M, Sottoriva A, Spiteri I, Shibata D, Curtis C, Tavaré S, Shah SP, Anderson K, Navin N, Nik-Zainal S, Gerlinger M, Xu X, Campbell PJ, Wagle N, Komarova NL, Wodarz D, Turke AB, Durrett R, Moseley S, Diaz LA, Kreso A, Stephens PJ, Pang H, Chen J, Ye Y, Sun H, Shi G, Chapman PB, Kwak EL, Ljungman M, Lane DP, Perrimon N, Pitsouli C, Shilo BZ, Kerbel RS, Chung AS, Ferrara N, Baish JW, Hynes NE, Lane HA, Turner N, Grose R, Yun J, Ying H, Araten DJ, Kunkel TA, Zhou B-BS, Elledge SJ, Medema RH, Macůrek L, Derheimer FA, Kastan MB, Ciriello G, Cerami E, Sander C, Schultz N, Yeang $\mathrm{CH}$, McCormick F, Levine A, Sharma S V., Bell DW, Settleman J, Haber DA, McLeod HL, Brock DW, Lemmon MA, Schlessinger J, Arkin MR, Wells JA, Bienstock RJ, Besson A, Dowdy SF, Roberts JM, Morin PJ, He TC, Wetering M van de, Farmer H, Irshad S, Ashworth A, Tutt A, Grueneberg DA, Mao M, Kirkwood JM, Barrett T, Segal NH, Castle JC, Sampson JH, Matsushita H, DuPage M, Mazumdar C, Schmidt LM, Cheung AF, Jacks T, Challa-Malladi M, Hodi FS, Topalian SL, Dunn BK, Jegalian K, Greenwald P, Lopes LC, BarberatoFilho S, Costa AC, Osorio-de-Castro CGS, Colditz GA, Wolin KY \& Gehlert S (2013) Cancer genome landscapes. Science 339, 1546-58.

Walker DC \& Southgate J (2009) The virtual cell--a candidate co-ordinator for "middle-out" modelling of biological systems. Brief. Bioinform. 10, 450-461.

WHO (2016a) WHO | Cancer. WHO. Available at:

http://www.who.int/mediacentre/factsheets/fs297/en/ [Accessed June 9, 2016].

WHO (2016b) World Health Statistics 2016: monitoring health for the SDGs, sustainable development goals. , 1-136.

Willyard C (2016) Cancer: An evolving threat. Nature 532, 166-168.

You JS \& Jones PA (2012) Cancer Genetics and Epigenetics: Two Sides of the Same Coin? Cancer Cell 22, 9-20. 


\section{Figures}

Figure 1 Blind monks examining an elephant, Hanabusa Itcho,

https://en.wikipedia.org/wiki/Blind_men_and_an_elephant, 2016.

Figure 2 Core Cellular Pathways, Cancer Genome Landscapes, Vogelstein et al., 2013 29

Figure 3 Stochastic (replicative) factors versus environmental and inherited factors: R-tumor versus D-tumor classification, Variation in cancer risk among tissues can be explained by the number of stem cell divisions, Tomasetti \& Vogelstein, 2015 ........ 46 Figure 4 Discrete Stochastic Events in the Change from a Normal Cell to a Cancer Cell, Causality and Chance in the Development of Cancer, Luzzatto \& Pandolfi, 2015

\section{Tables}

Table 1 Search Terms and Keywords, Examples

Table 2 Most frequently expressed genes and related pathways, http://www.genecards.org/, 2016. Additionally, genes (in multiple matchings) PVT1 and UBD and CPSF1, MIR1234, MIR939, DLEU2, MIR15A, FCGR1A, FCGR1B, GABBR1, ZNF131, MATR3, and SNHG4 are identified to be related and possibly related to cancer, respectively.

Table 3 The Hallmarks of Cancer, A Synthesis, Hanahan \& Weinberg, 2011, Vogelstein et al., 2013, Torrente et al., 2016, Groten et al., 2016 50 


\section{Acknowledgements}

I would like to thank Prof. em. Dr. Drs. h.c. Roland Mertelsmann and

Prof. Dr. Dr. h.c. Christoph Borner for their intellectual input, stimulating discussions and constant and friendly encouragement.

Furthermore, I deeply appreciate the professional support, challenging discussions and the expertise in transforming medical and biological concepts into algorithms and highly instructive computer-assisted visualizations of Maximilian Georg, Oliver Worm, Dr. Boris Lau and Dr. Sascha Lange.

I am grateful to Evguenia Alechine for proofreading the manuscript. Last not least I would like to appreciate the generous scholarship for this project provided by the Biothera Foundation, Freiburg, Germany. 
